\title{
Article
}

\section{The Road to Victory in the UEFA Women's Champions League: A Multi-Level Analysis of Successful Coaches, Teams, and Countries}

Edson, Filho and Jean, Rettig

Available at http://clok.uclan.ac.uk/23867/

Edson, Filho ORCID: 0000-0002-8548-4651 and Jean, Rettig (2018) The Road to Victory in the UEFA Women's Champions League: A Multi-Level Analysis of Successful Coaches, Teams, and Countries. Psychology of Sport and Exercise, 39. pp. 132-146. ISSN 1469-0292

It is advisable to refer to the publisher's version if you intend to cite from the work. http://dx.doi.org/10.1016/j.psychsport.2018.07.012

For more information about UCLan's research in this area go to http://www.uclan.ac.uk/researchgroups/ and search for <name of research Group>.

For information about Research generally at UCLan please go to http://www.uclan.ac.uk/research/

All outputs in CLoK are protected by Intellectual Property Rights law, including Copyright law. Copyright, IPR and Moral Rights for the works on this site are retained by the individual authors and/or other copyright owners. Terms and conditions for use of this material are defined in the policies page. 
2 Manuscript accepted for publication at Psychology of Sport and Exercise. This

3 version may differ slightly from the version published by Psychology of Sport

4 and Exercise.

Accepted for publication: July $25^{\text {th }}, 2018$

\section{*Corresponding Author:}

Edson Filho, PhD.

Lecturer (Assistant Professor) in Sport and Exercise Psychology

School of Psychology

University of Central Lancashire

Darwin Building 114

Preston PR1 2HE

United Kingdom

Tel: +44 (0) 1772893436

Email: efilho@uclan.ac.uk 


\section{Abstract}

37 Objectives: To explore coach-level, team-level, and country-level factors associated with

38 performance in the UEFA Women's Champions League.

39 Design: This study involved archival analysis of factual data on teams and coaches participating

40 in the UEFA Women's Champions League (2011-12 until 2015-16).

41 Method: Official data records were provided by UEFA. Hierarchical linear modeling analysis

42 was used to predict performance in the UEFA Women's Champions League. Specifically,

43 coaches' characteristics (level-1 variables), team factors (level-2 variables), and country

44 information (level-3 variables) were tested as predictors of performance (final rank, ranging from

451 to 32$)$.

46 Results: Data analysis yielded a two- and three-level solution. The two-level solution was

47 deemed more realistic and applied, and was chosen as the omnibus final model. Within the two-

48 level solution, years coaching experience in Champions League at level-1 $\left(\gamma_{10}=-2.90\right)$, and

49 number of times team has won Champions League $\left(\gamma_{01}=-7.13\right)$ and number of international

50 players $\left(\gamma_{02}=-1.08\right)$ at level-2, predict final performance at the UEFA Women's Champions

51 League (i.e., negative coefficient is indicative of performance improvement).

52 Conclusions: Our findings suggest that the quality of the team, positive cross-cultural effects

53 from an international roster, and the experience of the coach are positively associated with

54 performance in the UEFA Women's Champions League.

55 Keywords: coaching, expert performance, women's football, UEFA Champions League,

56 hierarchical linear modeling 


\section{Highlights}

- Over $85 \%$ of the coaches in the UEFA Women's Champions League are male.

59

60

- More experienced coaches are more likely to be successful or, alternatively, successful coaches keep their jobs for a longer time.

62

- Successful teams at the UEFA Women's Champions League win because of the quality of the "team as a whole".

65

- Internationalization is a good thing. For every international player on the team, performance improved by about 1 position. 


\section{The Road to Victory in the UEFA Women's Champions League:}

\section{A Multi-Level Analysis of Successful Coaches, Teams, and Countries}

It is important to examine the profile of successful coaches as previous research has

72 suggested that coach behaviors influence team outcomes across domains of human performance

73 (Bloom, 1985; Côté \& Gilbert, 2009). It is also imperative to consider the role of team factors, as

74 intra-team characteristics (e.g., number of international players) have been shown to influence

75 performance in sports (Filho, Gershgoren, Basevitch, \& Tenenbaum, 2014). Broader

76 environmental factors, including country effects, have also been linked to expert performance in

77 sports (Salmela \& Moraes, 2003). Given the paucity of research on the unique mechanisms of

78 expert performance in women's football, we aimed to examine the factors differentiating

79 successful coaches and teams from unsuccessful coaches and teams in the Union of European

80 Football Associations (UEFA) Women's Champions League, while accounting for the role of

81 country-level variables.

The uniqueness of the present study rests on examining excellence in women's

83 professional football, as most of the research in football has been focused on the men's game (for

84 a review see Gledhill, Harwood, \& Forsdyke, 2017). Previous research in sports has revealed

85 gender differences in team processes and performance (Carron, Colman, Wheeler, \& Stevens,

86 2002; Duda, 1987; Eagly \& Johnson, 1990; Filho, Tenenbaum, \& Yang, 2015; Fransen,

87 Vanbeselaere, Cuyper, Vande Broek, \& Boen, 2015; Leo, Sánchez-Miguel, Sánchez-Oliva,

88 Amado, \& García-Calvo, 2013). Specifically regarding the UEFA Champions League, previous

89 research has revealed large gender differences in physical and technical match performance

90 characteristics, such as distance covered by the players and pass completion rates (Bradley,

91 Dellal, Mohr, Castellano, \& Wilkie, 2014). 
We based our research on the notion that expert performance in sports is a multi-layered

93 phenomenon, and depends on inputs from various micro, meso, and macro levels of analysis

94 (Baker \& Farrow, 2017). In fact, several frameworks have been proposed to explain consistent

95 superior performance in sports (i.e., explanatory pluralism; see Dale, Dietrich, \& Chemero,

96 2009), with emphasis being placed on different variables and levels of analysis, including coach,

97 team, and contextual-level variables (for a review see Baker, Cobley, Schorer, \& Wattie, 2017).

98 Notwithstanding, the various conceptual frameworks on expertise have been primarily informed

99 by two research frameworks, namely the expert-novice paradigm and the expert performance

100 approach (Filho \& Tenenbaum, 2015). In the former, scholars seek to describe (descriptive

101 adequacy) variables related to expertise, whereas in the latter the focus is on identifying variables

102 that predict (explanatory adequacy) expert performance in sports. In the present study we sought

103 to both describe (through descriptive statistical analysis) and explain (through hierarchical linear

104 modeling) coach, team, and country-level factors related to performance at the UEFA Women's

105 Champions League.

106 Characteristics of Successful Coaches

107 Coach-level characteristics consider any variable related to the coach that may influence

108 sports performance, positively or negatively. To this extent, there is consensus that coaches with

109 different background characteristics (e.g., age, nationality status, international playing

110 experience) are more or less likely to be successful in sports (Côté \& Gilbert, 2009; Gilbert, Côté

111 \& Mallett, 2006; Starkes \& Ericsson, 2003). Previous research suggests that expert coaches have

112 athletic experience, participate in formal and informal educational programs, and have extensive

113 coaching experience (Erickson, Côté, \& Fraser-Thomas, 2007).

114 Previous research has also shown that competing in elite sport is an important 
115 denominator of successful coaches (e.g., Cregan, Bloom, \& Reid, 2007; Nash \& Sproule 2009;

116 Schinke, Bloom, \& Salmela, 1995). For instance, Gilbert and colleagues (2006) found that

117 successful coaches in interactive sports viewed themselves as high-performing athletes during

118 their playing careers. Overall, successful coaches tend to perceive themselves as "better than

119 average" athletes during their competitive careers (Gilbert, Lichtenwaldt, Gilbert, Zelezny, \&

120 Côté, 2009).

121 In addition to playing experience, formal education in a sport-related domain (e.g.,

122 Exercise Physiology, Physical Education, Sport Biomechanics, Sport Psychology), as well as

123 informal education opportunities, such as mentorship programs and networking with other

124 coaches, are important elements of successful coaches (Martens, 2012). Anderson and Gill

125 (1983) found that many expert coaches acquired their initial coaching knowledge while enrolled

126 in an undergraduate Physical Education degree. Interviews with high-performance coaches

127 across a range of team and individual sports revealed the importance of studying Physical

128 Education or Kinesiology and participating in formal coaching education courses (Carter \&

129 Bloom, 2009; Erickson, Côté, \& Fraser-Thomas, 2007).

130 Coaching experience also plays an important role in coaching development and expertise

131 (Cregan et al., 2007; Schinke et al., 1995). In interviews with Olympic coaches, coaching

132 experience at the national and international level was the most frequently cited variable in

133 preparation to become an elite coach (Gould, Giannini, Krane, \& Hodge, 1990; Gould, Hodge,

134 Peterson, \& Giannini, 1989). Expert basketball coaches outlined several developmental stages

135 that led to their current position, including novice coaching, developmental coaching, national

136 elite coaching, and international elite coaching (Schinke et al., 1995). Moreover, time in a given

137 coaching position (i.e., coach tenure and turnover) has also been linked to the development of 
138 expert performance in sports (De Paola \& Scoppa, 2008). Long-term coaches have more time to

139 develop shared mental models with players, which in turn might increase the likelihood of

140 positive outcomes (for a review see Mohammed, Ferzandi, \& Hamilton, 2010). A new coach, on

141 the other hand, may enhance motivation for players and provide beneficial changes in tactics and

142 playing styles (Höffler \& Sliwka, 2003).

\section{Characteristics of Successful Teams}

144 Successful sport teams tend to share certain characteristics. In other words, the quality of

145 players on the team, rather than the quality of coaches, might determine sport success

146 (Szymanski \& Kuypers, 1999). For instance, comparing a coach of an amateur team to a coach

147 of a professional team would not take into consideration the differences in the quality of the

148 players on each team. To this extent, previous studies examining football performance have

149 compared top to bottom teams, in line with the expert-novice paradigm (Filho \& Tenenbaum,

150 2015; Hirotsu \& Wright, 2003; Tenga, Holme, Ronglan, \& Bahr, 2010; Yates, North, Ford, \&

151 Williams, 2006). In the present study, we were interested in examining the effect of team quality

152 on performance in women's football, and thereby we explored the effects of the number of times

153 team has qualified for Champions League and number of times team has won Champions

154 League.

155 The bulk of empirical findings suggest that football teams can be successful by adopting 156 different playing styles, akin to the equifinality principle in human movement sciences (Schmidt, 157 McGown, Quinn, \& Hawkins, 1986). For instance, one team may succeed by playing offensive 158 style football (e.g., Brazil), whereas other teams may succeed by playing defensive football (e.g.,

159 Italy; see Filho, Basevitch, Yang, \& Tenenbaum, 2013). Notwithstanding, having skilled players

160 (i.e., players with task-related knowledge) on the roster seems paramount to team success 
161 irrespective of the playing style adopted by a given team (Mohammed et al., 2010). As such, in

162 the present study we were interested in analyzing whether the number of international players

163 and number of players with national team experience increased the likelihood of successful

164 performance at the UEFA Women's Champions League. On one hand, athletes with national

165 team experience have access to high-level competition experiences and are more likely to be

166 experts in their respective sport domains (Côté, Salmela, \& Russell, 1995). On the other hand,

167 international football players have been shown to perceive performance and team dynamics

168 differently than domestic athletes (Filho et al., 2014b), congruent with the overarching notion

169 that country-level effects influence athletic performance (Côté, Macdonald, Baker, \& Abernethy, 170 2006).

171 Characteristics of Successful Countries

172 The country in which the team hails from may also play a role in success (Salmela \&

173 Moraes, 2003). Certain countries have reputations for excellence in football in general, and 174 women's football in particular. In fact, since the inception of the men's FIFA World Cup in 175 1930, winners of the tournament have come from only eight countries (i.e., Argentina, Brazil, 176 England, France, Germany, Italy, Spain, and Uruguay. The picture is similar for the women's 177 game. Since the women's FIFA World Cup began in 1991 only four teams (i.e., Germany, Japan, 178 Norway, and the United States) have won the tournament.

179 The rate of success of different countries may depend on various factors, including the 180 popularity of the sport in the country (Salmela \& Moraes, 2003). The size of the country may 181 also impact the success of teams from that nation (Noll, 2002; Torgler, 2004). Teams from small 182 countries may have a competitive disadvantage compared to teams that hail from large countries 183 and thus benefit from having a greater number of football divisions, teams per division, and 
184 professional players (Dejonghe \& Vandeweghe, 2006).

185 Overall, myriad country-level variables may influence how teams play and coaches

186 develop and instruct, ultimately affecting the performance of club and national teams in

187 important international tournaments. Therefore, in the present study, we explored whether

188 several country-level variables (e.g., total number of divisions, number of teams in top division,

189 favorite team sport, budget for women's football) were predictive of performance at the UEFA

190 Women's Champions League.

\section{Research Questions \& Hypotheses}

192 The overarching research question guiding the present study was: "What is the profile of

193 winning teams in the UEFA Women's Champions League?" This question was proposed as a

194 broad exploratory inquiry stemming from the notion that coach, team, and country characteristics

195 are associated with excellence in sports. The specific research questions were:

196 (1) What coaches' characteristics are associated with successful performance in the UEFA Women's Champions League?

(2) What teams' characteristics are associated with performance in the UEFA Women's Champions League?

(3) What country characteristics are associated with performance in the UEFA Women's Champions League?

203 proposed:

204 (H1) Coaches' characteristics (level-1) were expected to predict performance in the 205 UEFA Women's Champions League. 
(H2) At least one team-level characteristic (level-2) was expected to add explanatory power to the final hierarchical linear model.

(H3) At least one country-level characteristic (level-3) was expected to add explanatory power to the final hierarchical linear model.

211 expert performance in sports. $\mathrm{H} 2$ and $\mathrm{H} 3$ are aligned with the notion that expert performance in

212 sports depends on team and country factors, and consistent with current methodological

213 guidelines on parsimonious hierarchical linear model estimation in which level-2 and level-3

214 variables must be added "one by one" to allow for the development of a parsimonious robust

215 model (see Raudenbush \& Bryk, 2002).

\section{Methods}

\section{Design}

218 This study involved archival analysis of factual data on teams and coaches participating 219 in the UEFA Women's Champions League (2011-12 until 2015-16). Country-level variables for 220 the same period were also taken into account. The final UEFA Women's Champions League 221 rank was the dependent variable, coaches' characteristics represented level-1 data, teams'

222 characteristics represented level-2 data, and country characteristics were included as level-3 data.

\section{Data Collection}

224 Official documents with information about the coaches, teams, and countries were 225 provided by UEFA, including team rosters and result sheets. Additional information was 226 gathered from the UEFA website, FIFA.com, and official country association websites. To this 227 extent, previous exploratory research on the predictors of performance in professional football

228 has relied on factual, publicly available online sources (Filho et al., 2013; Hirotsu \& Wright, 
2003).

Inclusion criteria. After reviewing the qualifying procedures for the tournament and

231 noting the number of teams that attempted to qualify each season (i.e., over 50 teams competed

232 for a spot in the Round of 32 in 2015-16), it was decided that the data input and analysis would

233 measure only the knockout stage of the tournament (Round of 32). In this way, the dependent

234 variable for the regression model (i.e., UEFA Women's Champions League final rank) would

235 have the same range (i.e., 1 to 32) for all seasons. Furthermore, it is important to note that the

236 structure of the UEFA Women's Champions League allows teams to submit different rosters for

237 each part of the tournament (e.g., Qualifying Round, Round of 32, Round of 16, Quarter-finals,

238 Semi-finals, and Final). Therefore, to be consistent across all teams, regardless of how far the

239 team advanced in the tournament, the coach- and team-level data was based on information for

240 the Round of 32.

241 With respect to the independent measures, all variables that were not consistently

242 recorded across levels of analyses for varying reasons (e.g., different countries reporting data

243 differently) were excluded from the data pool to ensure the analysis was performed on reliable

244 and valid information. Decisions on the inclusion/exclusion of any variable were made over a

245 series of peer-debriefing meetings involving the authors and "external judges" from UEFA who

246 are not authors of this manuscript. Any issues were discussed until consensus was reached. In

247 total, 11 variables were excluded from analysis. A detailed explanation for the rationale

248 supporting the exclusion of each variable is provided as Supplementary Material (Part 1).

\section{Data Input}

250 The dependent variable and independent variables related to the coach (level-1), team

251 (level-2), and country (level-3) included in the analysis are described in detail next. Data before 
252 the 2011-12 tournament was considered for coaches and teams. For instance, coach variables

253 exceed the 5-year interval considered for the dependent variable. By doing so, we accounted for

254 coaches and teams previous participation in the UEFA Women's Champions League since its

255 inception in 2009-10.

256 Dependent variable. Final rank for the UEFA Women's Champions League was

257 determined based on the official regulations of the game (see FIFA.com). Specifically, the

258 winner of the final match was ranked 1 and the finalist was ranked 2. All remaining teams were

259 ranked based on the official criteria put forth by FIFA: (1) Greatest combined goal difference in

260 all matches; (2) Greatest combined number of goals scored in all matches; and (3) If more than

261 one team remained level after applying the above criteria, their final ranking was determined

262 based on how far the team that they were eliminated by advanced in the tournament. If the teams

263 that were tied were beaten by teams that advanced to the same round of the tournament, then the

264 greatest combined goal difference in all matches for the advanced team was used to separate the 265 tie.

266 Independent coach-level variables. Coach-level variables included age, gender,

267 nationality status, former professional player, full national team playing experience,

268 international playing experience, position as a player, coaching experience of a national team,

269 years coaching experience in Champions League, and time at current position (Table 1).

270 Age. Age, in years, was calculated based on the date of birth for each coach listed on the

271 official UEFA roster.

272 Gender. Gender was included to examine whether differences exist between male and

273 female coaches. 
Nationality status. The coach's nationality status was coded according to whether they coached a team from their native country or a team from outside their native country.

Former professional player. Whether the coach was a former professional football player

277 was included as a measure of playing experience. Of note, this variable represented the highest

278 level of playing experience the coach achieved during his/her career.

$279 \quad$ Full national team playing experience. The coach's involvement as a player in his/her

280 full national team was recorded based on information from national team rosters available online.

281 International playing experience. It was noted whether the coach competed at the

282 international level for his/her full national team (e.g., FIFA World Cup, Olympics, UEFA

283 Champions League).

284 Position as a player. It was also considered whether successful football coaches were

285 more likely to have played a certain position. Performance roles and expectations differ between 286 goalkeepers, defenders, midfielders, and forwards. Therefore, the position in which the coach 287 played during his/her career was coded for in the data.

289 the coach had experience as the head coach of a national team, including a youth or full national 290 team, from any country.

$291 \quad$ Years coaching experience in Champions League. The number of previous times each 292 coach was involved in the UEFA Women's Champions League was recorded as a measure of 293 previous coaching experience.

294 Time at current position. Time at current position, measured in years, was calculated for 295 each coach to assess whether team performance was related to the length of time the coach has 296 been in the position. 
Independent team-level variables. Team-level variables included number of times team has qualified for Champions League, number of times team has won Champions League, number of international players, and number of players with national team experience (Table 1).

Number of times team has qualified for Champions League. The number of times the team has qualified for the UEFA Women's Champions League reflects the experience of the 302 team in previous years.

Number of times team has won Champions League. The number of times the team has won the UEFA Women's Champions League title provides information about the past quality of 305 the team.

Number of international players. The number of international players on the roster might be related to the financial capacity of the team. Wealthier teams have the financial means to recruit talent from overseas.

Number of players with national team experience. The total number of players with national team experience was included as an indicator of the football quality of the club team. Independent country-level variables. Country-level variables included FIFA world

312 ranking, total number of divisions, number of teams in top division, number of registered female

313 players, favorite team sport, and budget for women's football (Table 1). All country-level

314 variables, with the exception of FIFA world ranking that was gathered from FIFA.com, were 315 official records provided by UEFA.

FIFA world ranking. The FIFA world ranking for the country of which the team is from

317 was included in order to account for the strength of women's football in the given country. It was 318 deemed important to consider the ranking for each country at the point closest to the start of the 319 UEFA Women's Champions League, as it was expected that this most accurately reflects the 
320 quality of football in the country at the given time. The ranking used for the analysis was the one 321 issued most immediately preceding the start of the UEFA Women's Champions League

322 knockout round. For instance, for the 2015-16 competition, the rankings were from September

32325,2015 and the knockout stage started on October 7, 2015. The same procedure was applied to 324 all other seasons (i.e., 2011-12 to 2014-15).

325 Total number of divisions. To explore differences in league structures across countries, 326 the total number of divisions in the domestic women's football league was included in the model.

327 Number of teams in top division. Given that the size of divisions also differs across

328 countries, the total number of teams in the top national division was included in the model.

329 Number of registered female players. The total number of registered female players,

330 above 18 years of age, for the current year was used to measure the popularity of women's

331 football in each country.

332 Favorite team sport. Whether football was the favorite team sport, based on media, 333 exposure, marketing and spectators, was included in the model to explore the potential effect of 334 popularity of women's football on the dependent variable.

335 Budget for women's football. The budget (in Euros) for women's football for each

336 country was included in the data set to assess whether the general financial status of the sport in

337 the country was related to performance in the UEFA Women's Champions League.

\section{Data Analysis}

The first step in data analysis involved dealing with missing data. Subsequently, 340 descriptive and hierarchical linear modeling analyses were applied to the data set.

Missing data. Only two variables (i.e., former professional player; position as a player)

342 were excluded from the data analysis due to a large percentage (over 30\%) of non-available 
343 information. Noteworthy, variables with up to $10 \%$ missing data points were treated, in line with

344 recommendations for quantitative research analysis (see Creswell, 2008). Specifically, missing

345 data was treated in three ways: (1) for dummy variables, missing data was coded as "0" ("no" or

346 the absence of the attribute), thus reflecting a conservative approach in inference making; (2) for

347 continuous variables, the median was computed to avoid inflation resulting from outliers; and (3)

348 for budget for women's football interpolation was used on a case-to-case basis to determine the

349 values for the missing data.

350 Descriptive analysis. Descriptive analysis is particularly informative in census-like

351 inquiries, such as in the case of the present study (Creswell, 2008). Accordingly, measures of

352 central tendency, namely mean, median, and standard deviation, as well as natural frequency

353 counts, were performed.

354 Hierarchical linear modeling. The data for all seasons was analyzed together as the goal

355 was not to examine changes over time for particular teams but rather to conduct a census-like

356 analysis of the factors linked to success in the UEFA Women's Champions League. Potential

357 carry-over effects were not an issue as we explored the effects of level-1, level-2, and level-3

358 variables over the time span analyzed. It follows that a three-level hierarchical linear model was

359 tested. Figure 1 is a schematic descriptive summary and graphic representation of all variables

360 considered in the hierarchal linear modeling analysis.

$361 \quad$ For the null unconditional model, all dummy coded variables were treated as fixed

362 effects, whereas continuous variables were initially conceptualized as random effects in the

363 tested model. Furthermore, across the three levels of analysis, all variables were treated as raw,

364 non-centered scores, given that there was (1) an interest in estimating the unique contribution of 
each predictor, and (2) no occasion in which a value of zero represented either an undesirable or an unreasonable score (see Raudenbush \& Bryk, 2002).

\section{Results}

Congruent with the importance of describing (expert-novice paradigm) and explaining (expert performance approach) potential mechanisms linked to expert performance in sports, we multi-level analysis in a step-by-step mode, from the null unconditional model until the final

372 parsimonious model.

\section{Descriptive Analysis for Coaches}

For demographic factors (Table 2), the descriptive analysis revealed that the coaches

375 were in their early forties $(M=43.51 ; \mathrm{SD}=9.95)$, were mostly male $(85.60 \% ; \mathrm{n}=137)$, and

376 primarily coached a team in their native country rather than a foreign country. A post-hoc chi-

377 square analysis (see Garcia-Pérez \& Núñez-Antón, 2003) confirmed that the proportion of male

378 coaches was statistically greater than the proportion of female coaches $(\chi 2(5)=186.39, p<$

379.001 ), and the magnitude of this difference was found to be large (Cohen's $d=2.03$ ).

380 With respect to coaches' previous experience as football players (see Table 2), the

381 majority of the coaches were not former professional players $(54.10 \%, \mathrm{n}=59)$. Noteworthy, for

382 the most part $(88.90 \%, \mathrm{n}=136)$ coaches with professional playing experience did not play at a

383 premier international level competition, such as the FIFA World Cup, Olympics, or UEFA

384 Champions League. Coaches with previous playing experience at any level were mostly

385 midfielders $(43.10 \%, \mathrm{n}=31$; see Figure 2$)$. The proportion of midfielders was found to be

386 greater than the proportion of former goalkeepers and defenders $\chi^{2}(2)=10.90, p<.01$, but did

387 not differ significantly from the proportion of forwards, $\chi 2(1)=1.13, p=.29$. 
With respect to the coaches' coaching experience (Table 2), the descriptive analysis revealed that most of them were at their current club in a head coach capacity for about three years $(\mathrm{M}=3.36 ; \mathrm{SD}=4.51)$, and coaching for the first time in the UEFA Women's Champions

391 League $(\mathrm{M}=0.81 ; \mathrm{SD}=1.00)$. Over a third of the coaches $(37.10 \%, \mathrm{n}=56)$ had previously led a 392 youth or full national team.

\section{Descriptive Analysis for Teams}

Central tendency estimates and frequency counts for all level-2 team variables are

395 presented in Table 3. On average, teams had qualified for the UEFA Women's Champions

396 League two times $(\mathrm{M}=1.79 ; \mathrm{SD}=1.56)$. Furthermore, the teams had a median of 13 players

397 with national team experience, and the average team size was approximately 23 players $(\mathrm{M}=$

398 22.71; $\mathrm{SD}=2.19)$. The teams had around four international players on their rosters $(\mathrm{M}=4.40$;

$399 \mathrm{SD}=3.43)$. The majority of international players were from European countries $(66 \%$ out of 703

400 in total, $\mathrm{n}=469)$, followed by North American $(16 \%, \mathrm{n}=110)$, and African countries $(9 \%, \mathrm{n}=$

401 60; see Figure 3, Panel A). South American and Oceania countries accounted for 4\% $(n=30)$ of

402 the international trade each, with Asian nations accounting for the remaining $1 \%(n=9)$ of

403 foreign players. This trend was found to be consistent across all five years analyzed (Figure 3,

404 Panel B). The proportion of European players was found to be greater than all other continents,

$405 \chi^{2}(5)=186.39, p<.001$. The number of players from North America was found to differ

406 significantly from the proportion of players coming from Africa, South America, Oceania, and

407 Asia, $\chi^{2}(4)=20.48, p<.001$. No other statistically significant differences were observed when

408 comparing the proportion of international players across continents. 


\section{Descriptive Analysis for Countries}

Central tendency estimates and frequency counts for all level-3 country variables are

412 presented in Table 4. Teams were from countries with a large range of FIFA world rankings.

413 Across countries, the average number of football divisions was approximately four $(\mathrm{M}=4.21$;

$414 \mathrm{SD}=2.06)$, with the average number of teams in the top division being about $10(\mathrm{M}=10.55 ; \mathrm{SD}$

$415=2.60)$. The number of registered female football players, over age 18, varied greatly among

416 countries and was roughly $21,000(\mathrm{M}=21,287 ; \mathrm{SD}=24,216)$. However, this value is not

417 particularly informative as the variance was larger than the mean, likely because Europe is

418 comprised of countries with varying sizes and socio-economic characteristics. Also, noteworthy,

419 football was the favorite sport in approximately $60 \%$ of the countries $(59.70 \% ; n=92)$, with the

420 budget allotted to women's football being, on average, close to four million Euros per year

421 (Median $=2,500,000 ; \mathrm{M}=3,953,011 ; \mathrm{SD}=4,152,050)$. Altogether, the country-level data was

422 marked by wide variability, thereby corroborating the importance of accounting for country

423 specificity in line with multi-level analysis guidelines.

\section{$424 \quad$ Hierarchical Linear Modeling}

425 First, correlation analyses were performed among the independent variables included in 426 the analysis and the dependent variable (see Supplementary Material - Part 2). Overall, a linear

427 relationship was observed, thus attesting the application of hierarchical linear modeling analysis 428 to the data set (see Raudenbush \& Bryk, 2002). For brevity, only the omnibus final model is 429 defined in the text. The statistical definitions and coefficients for all models, including the 430 intermediate models not detailed in the text, are given as Supplementary Material (Part 3) in the 431 order in which they were ran. 
Null unconditional model. Initially, the null unconditional model with two levels and no independent variables was tested. The fixed and random effect estimates for the null

434 unconditional model are presented in Table 5. The reliability estimate for this model indicated 435 that $19 \%$ of the variance of final rank for the UEFA Women's Champions League was due to 436 between-team variables. The grand mean estimate was significant at $17.75(\mathrm{CI}=19.72,15.77)$, 437 and thus near the median value (final ranking $=16$, as there are 32 teams) for the final ranking 438 across all teams. There was no significant effect for the variance components, thus suggesting the 439 adoption of a fixed effect model for the subsequent models.

440 Level-1 modeling. Model A included all level-1 coach variables. The coefficients, 441 standard errors, t-ratios and $p$-values for all tested variables are presented in Table 6. Based on 442 the results of Model A (Table 6), the next step involved advancing a more parsimonious model. 443 Specifically, congruent with guidelines on parsimonious statistical modeling (see Cohen, West, 444 \& Aiken, 2002), Model B contained only the level-1 significant predictor of final rank: years 445 coaching experience in Champions League (see Table 7). Within Model B (Table 7), every 446 additional year of coaching experience in Champions League was found to improve final rank by 4473.63 positions $\left(\gamma_{70}=-3.63, p=.015\right)$. The intercept for Model B was estimated at $14.25(\mathrm{CI}=$ $44811.66,16.84)$ with the confidence interval encompassing the expected average value for final 449 ranking across all teams. Compared to Model A (Table 6), the reliability estimate for between450 teams decreased slightly to $17 \%$ after adding years coaching experience in Champions League to 451 the Model B. Nevertheless, computation of Pseudo R ${ }^{2}$ (see Raudenbush \& Bryk, 2002) indicated 452 that Model B explained 6.84\% more variance of final ranking than the null unconditional model 453 (Table 5) with no predictors. 
Level-2 modeling. This step involved the consideration of team-level variables.

Congruent with guidelines on parsimonious hierarchical linear modeling (Raudenbush \& Bryk, 2002), an a priori exploratory analysis was conducted to determine which significant level-2 predictors should be included in the model (see Supplementary Material - Part 3) in order to advance the best, yet most parsimonious two-level model. solution, wherein all predictors were statistically significant, was reached. Results for this model,

461 namely Model C (Table 8), suggested that years coaching experience in Champions League at

462 level-1, and number of times team has won Champions League and number of international

463 players at level-2, were significant predictors of final rank. Specifically, for every additional year 464 of experience coaching in the Champions League, final rank improved by approximately three 465 positions $\left(\gamma_{10}=-2.90, p=.038\right)$. Moreover, for every time a team raised the Champions League 466 trophy, final rank was estimated to improve by seven positions $\left(\gamma_{01}=-7.13, p<.001\right)$. Finally, 467 every international player on the roster represented an improvement in final rank by about one 468 position $\left(\gamma_{02}=-1.08, p<.001\right)$. The intercept for the model was significant at $24.56(\mathrm{CI}=21.76$, $46927.36)$

470 Level-3 modeling. To test whether a three-level model was required or whether a two471 level model would suffice, variance was fixed at “.19” (see Raudenbush \& Bryk, 2002), which 472 was the reliability estimate for Model C (Table 8), and an exploratory analysis of all level-3 473 predictors was conducted (see Supplementary Material - Part 3).

474 The variables found to be statistically significant at level-1 (i.e., years coaching 475 experience in Champions League) and level-2 (i.e., number of times team has won Champions 476 League; number of international players) were then added to the hierarchical regression analysis, 
477 along with FIFA world ranking at level-3, which was found to significantly predict final rank

478 (Table 9). The intercept for the model was estimated at $21.85(\mathrm{CI}=18.86,24.84)$, with the

479 reliability estimate for level-2 suggesting that $12 \%$ of the variation in the means of final rank was

480 due to true variation between countries. Importantly, in this three-level solution, years coaching

481 experience in Champions League was no longer found to be a significant predictor of final rank.

482 Final model. Both the three-level solution given in Table 9 and the two-level solution 483 presented in Table 8 are suitable omnibus models to explain final rank for the UEFA Women's

484 Champions League. Importantly, reliance on statistical guidelines for model estimation does not

485 provide a straightforward answer for deciding between two alternative non-equivalent models

486 (Raudenbush \& Bryk, 2002). On the one hand, arguments can be developed in favor of choosing

487 better-fit indices (see Stapleton, 2006), in which case the three-level solution given in Table 9

488 would be preferable as Pseudo $\mathrm{R}^{2}$ computation indicates that this model accounted for an

489 additional $55.23 \%$ of the variance of final ranking scores. On the other hand, arguments can be

490 developed in favor of the more parsimonious two-level solution given in Table 8 (Gigerenzer,

491 2010; Tenenbaum \& Filho, 2015). Every time you add factors to a model, the complexity of the

492 model increases (over parameterization) and its applicability tends to decrease.

To reach a decision between the two alternative solutions, the estimated impact of the

494 level-3 and level-1 predictors on the criterion final rank were analyzed in detail. In regard to a 495 three-level solution (Table 9), the median effect of FIFA world ranking on final ranking was

496 close to a two-position downgrade $\left(\gamma_{001}=0.09 * 17.5=1.58\right)$, with numerous effects in between

497 being possible (Figure 4, Panel A). Regarding a two-level solution (Table 8), the estimated

498 average effect of years coaching experience in Champions League on final ranking is about a

499 two-position upgrade $(\gamma 10=-2.90 * .81=-2.35)$. This effect was found to be linear over time 
500 (Figure 4, Panel B), influencing final ranking by a maximum of approximately twelve positions

501 for coaches with four years of experience in the league $\left(\gamma_{10}=-2.90 * 4=11.60\right)$, as per the

502 observed range for this variable (Table 2). Given that the impact of years coaching experience in

503 Champions League is more substantial than the impact of FIFA world ranking on final rank, a

504 final choice for a two-level solution is proposed herein (see Figure 5) and defined below:

\section{Level-1 Model}

Final rank $k_{i j}=\beta_{0 j}+\beta_{1 j} *($ Years coaching experience in Champions League $)+r_{i j}$

\section{Level-2 Model}

508

$\beta_{0 j}=\gamma_{00}+\gamma_{01} *($ Number of times team has won Champions League $)+\gamma_{02} *($ Number of

$$
\text { international players })+u_{0 j}
$$

$$
\beta_{1 j}=\gamma_{10}
$$

$511 \beta_{0 j}$ : The predicted final rank mean controlling for the number of previous Champions League

$$
\text { wins and the number of international players on a given team } \mathrm{j}
$$

$513 \beta_{1 j}$ : The predicted change in final rank for every year of coaching experience in the Champions

$$
\text { League for a given coach } \mathrm{i} \text { in a given team } \mathrm{j}
$$

$$
\gamma_{02}: \text { The average change in final rank for every international player on a given team } \mathrm{j}
$$


523 Considering the final coefficients estimated for this study (Table 8), the lowest "error free"

524 hypothetical final rank value consists of a coach with no previous experience in the league, 525 coaching a team with no previous league title, and without any international players on the roster 526 according to the equation:

$$
\text { Final rank }=24.56+(-2.90) *(0)+-7.13 *(0)+-1.08(0)
$$

Variations in the final rank value would depend on the number of previous years of 529 experience in the UEFA Women's Champions League by a given coach, a team with up to two 530 overall UEFA Women's Champions League titles within the past five years, and with a

531 maximum number of 15 international players on the roster. Again, the reported coefficients are

532 fixed rather than random and apply to the studied population given the range of the variables.

\section{Discussion}

534 The purpose of this study was to explore coach, team, and country factors linked to 535 performance in the UEFA Women's Champions League. To this end, descriptive statistics and 536 hierarchical linear modelling was applied to a data set spanning five seasons, for the three537 aforementioned levels of analysis. The main observed findings are discussed next.

\section{Descriptive Analysis for Coaches}

Our analysis revealed that the coaches were in their early forties. To coach at a high level

540 of performance, previous experience in the sport seems compulsory. To illustrate, over a third of

541 the coaches reported previous coaching experience of a full or youth national team. Hence, it is

542 unlikely that early professionals will be managing a women's team in the premier football

543 tournament in Europe. This is often the case in other domains of human performance as well, as

544 individuals tend to peak in certain careers at very specific age intervals, or "sensitive windows"

545 (see Bloom, 1985; Munakata, Casey, \& Diamond, 2004). Particular to coaching and 
management, in a classic study profiling the characteristics of over 1,000 executives, Bantel and Jackson (1989) observed that CEOs from large corporations were in their forties on average. Whereas previous experience seems to be essential to lead premier football clubs in the

549 UEFA Women's Champions League, the type of experience might differ across individuals. In 550 particular, the statistical analysis revealed that former professional players were not more likely 551 to coach in the league than those with no previous professional experience as a player. Thus, the 552 pathways to become a coach in the UEFA Women's Champions League seem to vary, akin to 553 the equifinality principle (see Von Bertalanffy, 1968), which purports that expert performance 554 can be reached through different routes. This finding bears implication for the on-going global 555 debate on coaching education (see Vargas-Tonsing, 2007), as it suggests that different types of 556 experience (e.g., former professional player, explicit academic training, formal coaching 557 education) can lead individuals to coaching at the highest competitive level.

558 It is noteworthy, however, that the majority of coaches with playing experience at any 559 level used to play as midfielders. Coaches who played as a midfielder might have a greater 560 chance of leading an elite women's football club in Europe. Midfielders have been found to 561 perceive performance requirements differently than players from other positions (i.e., 562 goalkeepers, defenders, and forwards) likely because midfielders are, in a sense, a hybrid 563 position that shares both defensive and offensive responsibilities (Filho et al., 2014b). As such, 564 former midfielders might have developed a better understanding of the game in both its 565 defensive and offensive requirements. Moreover, previous research has shown that athletes that 566 play in centralized positions have more access to information, and thus are more likely to 567 facilitate team coordination and performance by communicating shared and complementary 568 information to their teammates (Filho, Gershgoren, Basevitch, Schinke, \& Tenenbaum, 2014a). 
Noteworthy, our analysis revealed that there were significantly more male than female coaches in the league. This finding echoes previous research in the field in that women coaches'

571 report difficulties in progressing to a high-ranking coaching status in professional sports

572 (Norman, 2013). In particular, women coaches have noted that advancing to high-performance

573 coaching positions is difficult likely because of implicit gender biases, as coaching in sports is

574 dominated by men (Norman \& Rankin-Wright, 2016; Rankin-Wright, Hylton, \& Norman, 2017).

575 It is therefore important to support initiatives to increase the number of women in leadership 576 positions in sports and other domains of human performance (Blau, 2016). Particularly with 577 regards to women's football, policies should be continually developed to encourage former 578 female players to seek the necessary licenses and qualifications to pursue a career in coaching.

579 Examining the effectiveness of gender equality policies currently in place is also paramount to 580 ensure women take on leadership positions across domains of human performance (see Burton, $5812015)$.

It is important to highlight that only about $10 \%$ of the coaches were from international

583 countries. There are limited financial resources in women's football and this might shed light on

584 the relatively low frequency of international coaches at the knockout round of the UEFA

585 Women's Champions League. Availability of financial resources may also explain job stability

586 in the analysed sample. Coaches were found to serve in their current position for over three years

587 on average, thus signalling a smaller coaching turnover than that observed in the men's game

588 (see De Paola \& Scoppa, 2008). This finding might explain why coach tenure was positively 589 linked to performance. Over time, coaches get to know their player and teams, and thus are able 590 to foster the development of various team processes (e.g., cohesion, team mental models, 
591 collective efficacy) while devising more effective performance strategies (Balduck, Prinzie, \&

592 Buelens, 2010; Shamsie \& Mannor, 2013).

593 Descriptive Analysis for Teams

Frequency counts revealed that only three teams had won the UEFA Women's

595 Champions League within the 5-year span analysed. Accordingly, there is evidence that "hubs of

596 expertise" occur and are dominant within the European league network. As per the Pareto law,

$59780 \%$ of outcomes tend to come from $20 \%$ of the inputs. It follows that qualitative analysis of

598 these highly successful cases is warranted as previous research suggests that studying the modus

599 operandi of a few expert teams can yield important insights to inform the development of less

600 successful teams (see Gershgoren, Filho, Tenenbaum, \& Schinke, 2013).

601 Although few teams had earned the title, the teams had on average two years of

602 experience participating in the UEFA Women's Champions League. This suggests that the

603 quality of the team is paramount. Skill matters in the quest for success, which is why companies

604 from all domains seek to hire and retain highly qualified employees (Lockwood \& Ansari, 1999).

605 In fact, the team-level data suggests that teams in the UEFA Women's Champions League have

606 top quality players, with an average of over 12 players with national team experience per team.

607 This finding opens another question pertaining to the direction of this putative

608 relationship: Do players that play for their national teams join the best club teams in Europe or

609 does playing on a strong team in the UEFA Women's Champions League increase a player's

610 chance of being invited to join her national team? It is likely that a reciprocal relationship occurs,

611 wherein playing on a top club team increases the players' visibility to join her respective national

612 squad and vice-versa: playing on a national team increases the chance of being hired by a leading

613 football club in Europe. Also noteworthy, countries with more or less tradition in football 
614 produce players of more or less quality. In other words, hiring players from soccer powerhouse 615 countries (e.g., Brazil, England, Germany, the United States) might be more impactful than

616 hiring players from less traditional soccer nations. As discussed above, there is a grand influx of

617 players from the United States, which currently is the dominant country in women's football.

618 On average, teams had just over four international players on their squad. This figure is

619 likely constrained by the fact that European countries regulate the number of players outside

620 Europe that can play in their leagues (see Flores, Forrest, \& Tena, 2010). While the number of

621 players is a constrained factor, the origin of the players is a "free parameter", mainly shaped by

622 the unique dynamics of women's football. Specifically, the majority of international players at

623 the UEFA Women's Champions League come from North America, particularly the United

624 States, who has been the major force in women's football for the past decade. As is the case with

625 many job markets, local protective measures along with the strength of the marketplace in other

626 countries establish the migration flow of workers around the globe (Greenwood, 2014).

\section{Descriptive Analysis for Countries}

628 Across the 35 countries represented in the UEFA Women's Champions League over the

629 5-year span analyzed, football was found to be the favorite team sport among women. In the

630 past, football has been stereotypically associated with male rather than female socially desirable

631 traits (Azzarito, Solmon, \& Harrison, 2006). However, a positive shift has been noticed more

632 recently, with an increasing number of girls and women playing football around the globe (Lunz,

633 2007). It is important that researchers and practitioners continue to observe how societal and

634 cultural changes (e.g., gender rights movement) influence sport play and choice for women in 635 different countries. 
All other country-level variables were characterized by wide variability. In fact, from the

FIFA world ranking to total number of divisions and number of teams in top division, great

638 dispersion in the data pool was the major trend observed. Scattered data patterns were also

639 noticed for number of registered female players and budget for women's football among the 35

640 countries that were analysed. Together, these findings suggest that heteroscedasticity in the

641 organization of national leagues as well as the economics of football is part of the women's game

642 in Europe. Hence, the recommendation derived from these findings is that scholars and

643 practitioners should continue to account for country-level factors when studying expertise among

644 individual sport actors, such as coaches in the present study, and teams at large.

\section{Multi-Level Effects: Coaches within Teams within Countries}

Agents at one level are systems at another level (Von Bertalanffy, 1968). For this reason,

647 mapping cross-level effects allows for a deeper understanding of optimal performance across

648 domains of human interest, including football (Filho et al., 2014b). In the multi-level analysis

649 applied herein, the results support the hypotheses that coach- and team-level variables are related

650 to performance in the UEFA Women's Champions League for a two-level solution, and that

651 team-level factors and country-level factors are paramount within a three-level solution. From a

652 three-level perspective, countries with higher FIFA world rankings have better teams that are

653 more likely to be successful regardless of their coaches, in comparison to weaker teams from less

654 traditional football countries. From a two-level view, coaches with more experience increase the

655 chances of victory in the UEFA Women's Champions League.

Experienced and successful coaches are also more likely to be recruited and retained by

657 better teams. Altogether, "reciprocal determinism” (see Bandura, 1997) from a socio-cognitive

658 standpoint or "affordances" (see Fajen, Riley, \& Turvey, 2009) from a naturalistic account might 
659 be at play here. Reciprocal determinism pertains to the notion that individual, group, and 660 contextual processes are intertwined and mutually influence one another. Within an affordance

661 view, changes to input throughout and output relations in a given system are more or less likely 662 depending on a set of constraints and initial values. For instance, it has been shown that success 663 in sports and other areas of human performance depends, in part, on place of birth (Côté et al., 664 2006). In all, countries influence the development of teams and coaches. Likewise, hiring 665 experienced coaches may influence the development of strong teams, which in turn may 666 influence the development of football over time in a given country.

667 Regardless of which view is adopted (the two-level solution proposed herein or the 668 aforementioned three-level alternative solution), the quality of the teams was found to matter the 669 most in predicting performance at the UEFA Women's Champions League. In other words, the 670 strongest predictive effects originate from the team-level of analysis. A team that has won the

671 UEFA Women's Champions League before is more likely to succeed again. In fact, previous 672 performance accomplishments are a major predictor of efficacy beliefs, which in turn are major 673 predictors of performance in team sports in general (Feltz, Short, \& Sullivan, 2008), and football 674 in particular (Filho, Tenenbaum, \& Yang, 2014c; Leo et al., 2013). To put plainly, success boosts 675 confidence, which in turn increases the chance of further success. Additionally, more successful 676 teams are likely more attractive to high-quality athletes motivated by the best chances to win 677 titles (Sanderson \& Siegfried, 1997).

678 The number of international players on the team was also found to predict final rank at 679 the UEFA Women's Champions League after analyzing several level-1 coach and level-3 680 country relevant variables. International players aggregate value to the team, as they perceive 681 performance differently, and apply different defensive and offensive tactics to football play 
682 (Filho et al., 2014b). Moreover, international football players are usually top-level athletes that

683 have left their native countries to take on more prosperous job opportunities in foreign nations

684 (Kleven, Landais, \& Saez, 2013). Similar to top-level engineers from around the world who are

685 hired by multinational corporations in Silicon Valley for instance, world-class foreign football

686 players are hired by European clubs to add value to their squads. To illustrate further, for part of

687 the 2015-16 season, Marta Da Silva (Brazil) and Carli Lloyd (United States), two the most

688 successful women football players of all times, played away from their homes for clubs in

689 Europe.

690 With respect to level-1 data, previous experience coaching in the UEFA Women's

691 Champions League was also found to predict final rank. Coaches that have competed in the

692 league before are likely more aware of the challenges that the competition imposes, such as

693 strategies to counter-act home field advantage and the away goals rule (i.e., goals scored at away

694 venues count more than goals scored at home). In effect, experience at the highest level of

695 competition is important in the development of expertise (Bloom, 1985; Côté et al., 1995;

696 Williams \& Ericsson, 2005). Previous experience allows one to develop mental representations

697 that can be applied before, during, and after decisive moments in sport competitions (Filho \&

698 Tenenbaum, 2015; Tenenbaum, Basevitch, Gershgoren, \& Filho, 2013). Put differently, once

699 exposed to high-pressure situations, individuals develop mental skills that allow them to self-

700 regulate and perform better the next time around.

701 With respect to level-3 data, expressive variability was observed across countries in all

702 measured variables. Hence, considering country-level factors is important in research on

703 women's football. However, the size and financial power of a country is not the major factor

704 predicting performance of teams at the UEFA Women's Champions League. In fact, previous 
705 research has shown that the size and financial power of a country does not necessarily explain 706 performance in football (Hoffmann, Ging, \& Ramasamy, 2002). Countries of smaller sizes and

707 budgets may also succeed in sports if the culture around that sport is strong enough. From the

708 present analysis, the only factor that might play a role in performance at the UEFA Women's

709 Champions League was the FIFA world ranking for a given country. More traditional countries

710 may perform better than less traditional ones. Thus, it is important to examine country-level

711 factors when studying performance in women's football. However, it is important to reiterate

712 that, for the present study, the quality of the team and the experience of the coach are paramount

713 for success in the UEFA Women's Champions League. That is, teams from less traditional

714 countries that have a winning story and an experienced coach may triumph in the end. The scope

715 of these findings, limitations, applied implications, and avenues for future research are discussed

716 next.

\section{Limitations and Strengths}

718 There are at least two limitations that need elaborating to orient future research in

719 women's football. As previously mentioned, the iterative model was fixed rather than random

720 and thus generalizability is limited to the variables tested within their respective ranges.

721 Moreover, this study was correlational in nature and, as such, inferences of causality are not

722 appropriate. Despite these limitations, this study advances the literature on women's football, as

723 the majority of research efforts in football have targeted the men's game. In the present study, an

724 inductive model of expert performance in women's football emerged from our data analysis

725 (Figure 5), addressing, at least in part, the call for empirical research geared towards developing

726 frameworks of expert performance in women's sports (see Gledhill et al., 2017). To this extent,

727 findings of this study contrasted many common notions in men's football, thus making it clear 
728 that gender effects exist in the "beautiful game" and that guidelines derived from men's football

729 do not necessarily apply to high-performance women's football. Also, notwithstanding the cross-

730 sectional nature of the study, the comprehensive census-like analysis presented herein provides

731 more than a "snapshot profile” of high-performance women's football in Europe. Natural

732 frequency counts revealed the current status of coaches, teams, and countries participating in the

733 league bringing to light, for instance, the small number of women coaches in the League.

734 Stakeholders should use the findings of this study to "think-act-reflect" (i.e., reflexive practice)

735 on best practice guidelines for coaches, teams, and countries. Awareness of factors related to

736 high-performance at the UEFA Women's Champions League is an important step to promote

737 positive (and evidence-based) changes in premier women's football.

\section{$738 \quad$ Future Research}

739 Future research could focus on studying expert coaches through qualitative lenses. As the

740 results have shown, the proportion of female coaches in the league is much smaller than the

741 proportion of male coaches. Accordingly, we echo the call for more studies on the challenges

742 that women face in pursuing a professional coaching career in sports (see Norman, 2013;

743 Norman \& Rankin-Wright, 2016; Rankin-Wright et al., 2017). In particular, additional research

744 on the intersections of gender and other minority statuses (e.g., race/ethnicity) among football

745 coaches is warranted. More studies on the migration flow of international athletes are also

746 warranted. As the findings illustrate, the immigration flow of football players at the UEFA

747 Women's Champions League contrasts with what is known about the male player migration (see 748 Elliott \& Harris, 2014). Also, the effect of the team's budget on performance variables should be

749 examined. In the present study, budget for women's football was modelled at the country-level

750 of analysis, not the team-level. It is likely that the quality and number of international players on 
751 the team, factors that have been found significant in the present study, co-vary with the team's

752 annual operating budget. However, it might be challenging to obtain this information, as teams

753 might not be willing to disclose financial data.

754 Future research should look beyond the demographic characteristics of coaches and

755 teams by addressing the multi-layered relationship among latent individual psychological factors

756 ("I" factors, such as personality) and team processes (e.g., cohesion, collective efficacy).

757 Furthermore, while it is unclear whether a general theory of expertise will ever be developed

758 (Farrow \& Baker, 2018), scholars should continue to work towards theoretical integration in

759 research on expert performance in sports. An integrated yet parsimonious model of expertise in

760 team sports might help to inform research and practice in sport psychology.

\section{$761 \quad$ Applied Implications}

762 Our analysis revealed that individual and team-level factors should be taken into account

763 by practitioners working in women's professional football. Foremost, team-level factors are most

764 important in predicting successful performance at the UEFA Women's Champions League. As

765 such, sport professionals should think about interventions that address "the team first".

766 Specifically, drafting players from traditionally successful teams as well as international players

767 may increase the chance of winning games at the UEFA Women's Champions League. Former

768 winners and international players bring the experience and confidence that propels performance

769 in high-level competitions. Practitioners wanting to promote peak performance in women's

770 football should also consider developing "cultural intelligence" interventions aimed at promoting

771 cross-cultural understanding in teams with numerous international players on their rosters.

772 The "team comes first", but our findings also revealed that coaching experience matters.

773 Accordingly, teams seeking to improve their performances in the UEFA Women's Champions 
774 League should also consider hiring coaches who have previous experience in the competition. As

775 discussed, previous high-stake experience fosters the development of mental representations,

776 which are the basis for effective cognitive, affective, and behavioral patterns differentiating

777 expert individuals and teams from their less successful counterparts. Alternatively, teams could

778 work towards developing their coaches by reducing turnover and providing opportunities for

779 continued education and "learning the job while doing the job", rather than emphasizing an

780 immediate outcome. Repeated participation in the UEFA Women's Champions League may

781 equip coaches with the experience needed to help teams perform better over time.

782 Finally, the findings of this study reinforce the importance of governing bodies and

783 Football Associations in developing (a) coaching education programs tailored to the specific

784 needs of women's football; (b) initiatives to increase the number of women coaching high-

785 performance football teams; and (c) campaigns publicizing the benefits of cultural diversity in

786 sports. Governing bodies should consider ways to promote "competitive balance" in order to

787 avoid a few teams consistently winning the championship, which negatively impacts the

788 economic sustainability of other teams (Sanderson \& Siegfried, 2003). To conclude, we call for

789 comprehensive multi-levels of analysis studies on expert-performance across domains of human

790 interest. By examining multi-level effects it is possible to advance knowledge on how to foster

791 talent at the individual level of analysis, while promoting the development of expert teams, and

792 advancing country-level policies to promote quality sport play around the world. 
794 Anderson, D. F., \& Gill, K. S. (1983). Occupational socialization patterns of men's and women's 795 interscholastic basketball coaches. Journal of Sport Behavior, 6, 105-116.

796 Azzarito, L., Solmon, M. A., \& Harrison Jr, L. (2006). “... If I had a choice, I would....” A 797 Feminist poststructuralist perspective on girls in physical education. Research Quarterly $798 \quad$ for Exercise and Sport, 77, 222-239.

799 Baker, J. Cobley, S., Schorer, J., \& Wattie, N. (2017). Routledge handbook of talent identification and development in sport. New York, NY: Routledge.

801 Baker, J., \& Farrow, D. (2017). Routledge handbook of sport expertise. New York, NY: Routledge.

Balduck, A., Prinzie, A., \& Buelens, M. (2010). The effectiveness of coach turnover and the effect on home team advantage, team quality and team ranking. Journal of Applied Statistics, 37, 679-689. https://doi.org/10.1080/02664760902824731

Bandura, A. (1997). Self-efficacy: The exercise of control. New York, NY: WH Freeman/Times Books/Henry Holt.

Bantel, K. A., \& Jackson, S. E. (1989). Top management and innovations in banking: Does the composition of the top team make a difference? Strategic Management Journal, 10, 107124. Press.

813 Bloom, B. S. (Ed). (1985). Developing talent in young people. New York, NY: Ballantine.

814 Bradley, P. S., Dellal, A., Mohr, M., Castellano, J., \& Wilkie, A. (2014). Gender differences in 
Running head: SUCCESS IN UEFA WOMEN'S FOOTBALL

League. Human Movement Science, 33, 159-171. DOI: 10.1016/j.humov.2013.07.024

817 Burton, L. J. (2015). Underrepresentation of women in sport leadership: A review of research. Sport Management Review, 18, 155-165. https://doi.org/10.1016/j.smr.2014.02.004

819 Carron, A. V., Colman, M. M., Wheeler, J., \& Stevens, D. (2002). Cohesion and performance in 820 sport: A meta-analysis. Journal of Sport \& Exercise Psychology, 24, 168-188.

821 Carter, A. D., \& Bloom, G. A. (2009). Coaching knowledge and success: Going beyond athletic experiences. Journal of Sport Behavior, 32, 419-437.

823 Cohen, J., Cohen, P., West, S. G., \& Aiken, L. S. (2002). Applied multiple regression/correlation 824 analysis for the behavioral sciences (3rd ed.). London, United Kingdom: Routledge.

825 Côté, J., \& Gilbert, W. (2009). An integrative definition of coaching effectiveness and expertise.

826 International Journal of Sports Science \& Coaching, 4, 307-323. https://doi.org/10.1260/174795409789623892

828 Côté, J., Macdonald, D. J., Baker, J., \& Abernethy, B. (2006). When “where” is more important than "when": Birthplace and birthdate effects on the achievement of sporting expertise. Journal of Sports Sciences, 24, 1065-1073.

831 Côté, J., Salmela, J. H., \& Russell, S. (1995). The knowledge of high-performance gymnastic coaches: Methodological framework. The Sport Psychologist, 9, 65-75.

833 Cregan, K., Bloom, G. A., \& Reid, G. (2007). Career evolution and knowledge of elite coaches 834 835 of swimmers with a physical disability. Research Quarterly for Exercise and Sport, 78, 339-350. DOI: 10.1080/02701367.2007.10599431 and qualitative research. Newark, NJ: Pearson. 
838 Dale, R., Dietrich, E., \& Chemero, A. (2009). Explanatory pluralism in cognitive science. Cognitive Science, 33, 739-942. DOI: 10.1111/j.1551-6709.2009.01042.x

Dejonghe, T., \& Vandeweghe, H. (2006). Belgian football. Journal of Sports Economics, 7, 105113.

De Paola, M., \& Scoppa, V. (2008). The effects of managerial turnover: Evidence from coach dismissals in Italian soccer teams. Munich, Germany: Munich Personal RePEc Archive.

Duda, J. L. (1987). Toward a developmental theory of children's motivation in sport. Journal of Sport Psychology, 9, 130-145.

Eagly, A. H., \& Johnson, B. T. (1990). Gender and leadership style: a meta-analysis. Psychological Bulletin, 108, 233-256. Chicago, IL: Routledge.

Erickson, K., Côté, J., \& Fraser-Thomas, J. (2007). Sport experiences, milestones, and educational activities associated with high-performance coaches' development. The Sport Psychologist, 21, 302-316. https://doi.org/10.1123/tsp.21.3.302

Fajen, B. R., Riley, M. A., \& Turvey, M. T. (2009). Information, affordances, and the control of action in sport. International Journal of Sport Psychology, 40, 79-107.

855 Farrow, D. \& Baker, J. (2018). The future of sport expertise research: barriers and facilitators in theory and practice. In J. Baker \& D. Farrow (Eds.), Routledge handbook of sport expertise (pp. 439-444). New York, NY: Routledge.

858 Feltz, D. L., Short, S. E., \& Sullivan, P. J. (2008). Self-efficacy in sport. Champaign, IL: Human Kinetics.

860 Filho, E., Basevitch, I., Yang, Y., \& Tenenbaum, G. (2013). Is the best defense a good offense? 
Comparing the Brazilian and Italian soccer styles. Kinesiology, 45, 213-221.

862

863

864

865

866

867

868

869

870

871

872

\section{3}

874

875

876

877

878

879

880

881

882

883

Filho, E., Gershgoren, L., Basevitch, I., Schinke, R., \& Tenenbaum, G. (2014a). Peer leadership and shared mental models in a college volleyball team: A season long case study. Journal of Clinical Sport Psychology, 8, 184-203. DOI: 10.1123/jcsp.2014-0021

Filho, E., Gershgoren, L., Basevitch, I., \& Tenenbaum, G. (2014b). Profile of high-performing college soccer teams: An exploratory multi-level analysis. Psychology of Sport \& Exercise, 15, 559-568. DOI: 10.1016/j.psychsport.2014.05.008

Filho, E., Tenenbaum, G., \& Yang, Y. (2014c). Cohesion, team mental models, and collective efficacy: towards an integrated framework of team dynamics in sport. Journal of Sports Sciences, 33, 641-653. DOI: 10.1080/02640414.2014.957714

Filho, E., \& Tenenbaum, G. (2015). Sports psychology. Oxford bibliographies. Oxford, United Kingdom: Oxford University Press.

Filho, E., Tenenbaum, G., \& Yang, Y. (2015). Cohesion, team mental models, and collective efficacy: towards an integrated framework of team dynamics in sport. Journal of Sports Sciences, 33, 641-653. DOI: 10.1080/02640414.2014.957714

Flores, R., Forrest, D., \& Tena, J. D. (2010). Impact on competitive balance from allowing foreign players in a sports league: Evidence from European soccer. Kyklos, 63, 546-557. DOI: $10.1111 / \mathrm{j} .1467-6435.2010 .00487 . \mathrm{x}$

Fransen, K., Vanbeselaere, N., De Cuyper, B., Vande Broek, G., \& Boen, F. (2015). Perceived sources of team confidence in soccer and basketball. Medicine \& Science in Sports \& Exercise, 47, 1470-1484. DOI: 10.1249/MSS.0000000000000561.

Garcia-Pérez, M. A., \& Núñez-Antón, V. (2003). Cellwise residual analysis in two-way contingency tables. Educational and Psychological Measurement, 63, 825-839. 
884 Gershgoren, L., Filho, E., Tenenbaum, G., \& Schinke, R. J. (2013). Coaching shared mental

885

886

887

models in soccer: A longitudinal case study. Journal of Clinical Sport Psychology, 7, 293-312. https://doi.org/10.1123/jcsp.7.4.293

Gigerenzer, G. (2010). Personal reflections on theory and psychology. Theory \& Psychology, 20, 733-743. http://dx.doi.org/10.1177/0959354310378184.

Gilbert, W. D., Côté, J., \& Mallett, C. (2006). Developmental paths and activities of successful sport coaches. International Journal of Sports Science \& Coaching, 1, 69-76. https://doi.org/10.1260/174795406776338526

Gilbert, W., Lichtenwaldt, L., Gilbert, J., Zelezny, L., \& Côté, J. (2009). Developmental profiles of successful high school coaches. International Journal of Sports Science \& Coaching, 4, 415-431. https://doi.org/10.1260/174795409789623928

Gledhill, A., Harwood, C., \& Forsdyke, D. (2017) Psychosocial factors associated with talent development in football: A systematic review. Psychology of Sport and Exercise, 31, 93112.

Gould, D., Giannini, J., Krane, V., \& Hodge, K. (1990). Educational needs of elite U.S. national teams, Pan American, and Olympic coaches. Journal of Teaching in Physical Education, 9, 332-344.

Gould, D., Hodge, K., Peterson, K., \& Giannini, J. (1989). An exploratory examination of strategies used by elite coaches to enhance self-efficacy in athletes. Journal of Sport \& Exercise Psychology, 11, 128-140.

Hirotsu, N., \& Wright, M. (2003). An evaluation of characteristics of teams in association football by using a Markov process model. The Statistician, 52, 591-602. 
906

907

908

909

910

911

912

913

914

915

916

917

918

919

920

921

922

923

924

925

926

927

928

Höffler, F., \& Sliwka, D. (2003). Do new brooms sweep clean? When and why dismissing a manager increases the subordinates' performance. European Economic Review, 47, 877890.

Hoffmann, R., Ging, L. C., \& Ramasamy, B. (2002). The socio-economic determinants of international soccer performance. Journal of Applied Economics, 5, 253-272.

Kleven, H. J., Landais, C., \& Saez, E. (2013). Taxation and international migration of superstars: Evidence from the European football market. The American Economic Review, 103, 1892-1924. DOI: 10.1257/aer.103.5.1892

Leo, F. M., Sánchez-Miguel, P. A., Sánchez-Oliva, D., Amado, D., \& García-Calvo, T. (2013). Analysis of cohesion and collective efficacy profiles for the performance of soccer players. Journal of Human Kinetics, 39, 221-229. DOI: 10.2478/hukin-2013-0085

Lockwood, D., \& Ansari, A. (1999). Recruiting and retaining scarce information technology talent: a focus group study. Industrial Management \& Data Systems, 99, 251-256.

Lunz, M. (2007). 265 million playing football. FIFA Magazine. 10-15. Available at https://www.fifa.com/mm/document/fifafacts/bcoffsurv/emaga_9384_10704.pdf

Martens, R. (2012). Successful coaching (4th ed.). Champaign, IL: Human Kinetics.

Mohammed, S., Ferzandi, L., \& Hamilton, K. (2010). Metaphor no more: A 15-year review of the team mental model construct. Journal of Management, 36, 876-910. https://doi.org/10.1177/0149206309356804

Munakata, Y., Casey, B. J., \& Diamond, A. (2004). Developmental cognitive neuroscience: progress and potential. Trends in Cognitive Sciences, 8, 122-128.

Nash, C. S., \& Sproule, J. (2009). Career development of expert coaches. International Journal of Sports Science and Coaching, 4, 121-138. https://doi.org/10.1260/1747-9541.4.1.121 
929 Noll, R. G. (2002). The economics of promotion and relegation in sports leagues: The case of 930 English football. Journal of Sports Economics, 3, 169-203.

931 Norman, L. (2013). The challenges facing women coaches and the contributions they can make 932 to the profession. International Journal of Coaching Science, 7, 3-23.

933 Norman, L., \& Rankin-Wright, A. J. (2016). Surviving rather than thriving: Understanding the 934 experiences of women coaches using a theory of gendered social well935 being. International Review for the Sociology of Sport.

936 Rankin-Wright, A. J., Hylton, K., \& Norman, L. J. (2017). Negotiating the coaching landscape:

937 Experiences of Black men and women coaches in the United Kingdom. International 938 Review for the Sociology of Sport.

939 Raudenbush, S. W., \& Bryk, A.S. (2002). Hierarchical linear models (2nd ed.). Thousand Oaks, $940 \quad$ CA: Sage Publications.

941 Salmela, J. H., \& Moraes, L. C. (2003). Development of expertise: The role of coaching, 942 families, and cultural contexts. In J. Starkes, \& K. A. Ericsson (Eds.), Expert $944 \quad$ Kinetics.

945 Sanderson, A. R., \& Siegfried, J. J. (1997). The implications of athlete freedom to contract:

946 Lessons from North America. Economic Affairs, 17, 7-12.

947 Sanderson, A. R., \& Siegfried, J. J. (2003). Thinking about competitive balance. Journal of $948 \quad$ Sports Economics, 4, 255-279.

949 Schinke, R. J., Bloom, G. A., \& Salmela, J. H. (1995). The career stages of elite Canadian $950 \quad$ basketball coaches. Avante, 1, 48-62. 
Running head: SUCCESS IN UEFA WOMEN'S FOOTBALL

951 Schmidt, R. A., McGown, C., Quinn, J. T., \& Hawkins, B. (1986). Unexpected inertial loading in 952 rapid reversal movements: Violations of equifinality. Human Movement Science, 5, 263-

953

Shamsie, J., \& Mannor, M. J. (2013). Looking inside the dream team: Probing into the 273.

Stapleton, L. M. (2006). Using multilevel structural equation modeling techniques with complex sample data. In G. R. Hancock \& R. O. Mueller (Eds.), Structural equation modeling: A second course (pp. 345-383). Charlotte, NC: Information Age Publishing.

Starkes, J., \& Ericsson, K. A. (Eds.). (2003). Expert performance in sports: Advances in research on sport expertise. Champaign, IL: Human Kinetics.

962 Szymanski, S., \& Kuypers, T. (1999). Winners and losers: The business strategy of football.

963 London, United Kingdom: Viking.

964 Tenenbaum, G., Basevitch, I., Gershgoren, L., \& Filho, E. (2013). Emotions-decision-making in sport: Theoretical conceptualization and experimental evidence. International Journal of Sport and Exercise Psychology, 11, 151-168. DOI: 10.1080/1612197X.2013.773687

Tenenbaum, G., \& Filho, E. (2015). Measurement considerations in performance psychology. In. psychology: Perception, action, cognition, and emotion (pp. 31-44). Philadelphia, PA:

971 Tenga, A., Holme, I., Ronglan, L. T., \& Bahr, R. (2010). Effect of playing tactics on achieving 972 score-box possessions in a random series of team possessions from Norwegian 973 professional soccer matches. Journal of Sports Sciences, 28, 245-255. DOI: 
975 Torgler, B. (2004). The economics of the FIFA football world cup. Kyklos, 57, 287-300.

976 Vargas-Tonsing, T. M. (2007). Coaches' preferences for continuing coaching

977 education. International Journal of Sports Science \& Coaching, 2, 25-35.

978 https://doi.org/10.1260/174795407780367186

979 Von Bertalanffy, L. (1968). General system theory. New York, NY: George Braziller Inc.

980 Williams, A. M., \& Ericsson, K. A. (2005). Perceptual-cognitive expertise in sport: Some 981 considerations when applying the expert performance approach. Human Movement

982 Science, 24, 283-307. https://doi.org/10.1016/j.humov.2005.06.002

983 Yates, I., North, J., Ford, P., \& Williams, M. (2006). A quantitative analysis of Italy’s World 984 Cup performances: A comparison of World Cup winners. Insight - The FA Coaches 985 Association Journal, 6, 55-59. 
986 Table 1

987

988

989

\section{Coding and Description for Variables}

\begin{tabular}{|c|c|c|}
\hline Variable & Data Source & Coding Description \\
\hline \multicolumn{3}{|l|}{ Coach-Level Variables } \\
\hline Age & $\mathrm{UEFA}^{\mathrm{a}}$ & Continuous \\
\hline Gender & Team website or sporting website & Dummy coded $; 0=$ male $; 1=$ female \\
\hline Nationality status & $\mathrm{UEFA}^{\mathrm{a}}$ & $\begin{array}{l}\text { Dummy coded; } 0=\text { coaches team from } \\
\text { outside native country; } 1=\text { coaches team } \\
\text { from native country }\end{array}$ \\
\hline Former professional player & Team website or sporting website & $\begin{array}{l}\text { Dummy coded; } 0=\text { did not play as a } \\
\text { professional; } 1=\text { played as a professional }\end{array}$ \\
\hline Full national team playing experience & Team website or sporting website & $\begin{array}{l}\text { Dummy coded; } 0=\text { did not play on full } \\
\text { national team; } 1=\text { played on full national } \\
\text { team }\end{array}$ \\
\hline International playing experience & Team website or sporting website & $\begin{array}{l}\text { Dummy coded; } 0=\text { did not play } \\
\text { internationally; } 1=\text { played in World Cup, } \\
\text { Olympics, or Champions League }\end{array}$ \\
\hline $\begin{array}{l}\text { Position as a player } \\
\quad \text { Goalkeeper; Defender; Midfielder; Forward }\end{array}$ & Team website or sporting website & Dummy coded; $0=$ no; $1=$ yes \\
\hline Coaching experience of a national team & Team website or sporting website & $\begin{array}{l}\text { Dummy coded; } 0=\text { did not coach a youth or } \\
\text { full national team; } 1=\text { coached a youth or } \\
\text { full national team }\end{array}$ \\
\hline Years coaching experience in Champions League & Team website or sporting website & Continuous \\
\hline Time at current position & Team website or sporting website & Continuous \\
\hline
\end{tabular}


991 Table \#1 - Continued

\begin{tabular}{|c|c|c|}
\hline Variable & Data Source & Coding Description \\
\hline$\underline{\text { Team-Level Variables }}$ & & Continuous \\
\hline $\begin{array}{l}\text { Number of times team has qualified for } \\
\text { Champions League }\end{array}$ & $\mathrm{UEFA}^{\mathrm{b}}$ & Continuous \\
\hline $\begin{array}{l}\text { Number of times team has won Champions } \\
\text { League }\end{array}$ & $\mathrm{UEFA}^{\mathrm{b}}$ & Continuous \\
\hline Number of international players & UEFA $^{\mathrm{a}}$ & Continuous \\
\hline Number of players with national team experience & Team website or sporting website & Continuous \\
\hline \multicolumn{3}{|l|}{ Country-Level Variables } \\
\hline FIFA world ranking & FIFA $^{\mathrm{c}}$ & Continuous \\
\hline Total number of divisions & $\mathrm{UEFA}^{\mathrm{d}}$ & Continuous \\
\hline Number of teams in top division & UEFA $^{d}$ & Continuous \\
\hline Number of registered female players & UEFA $^{d}$ & Continuous \\
\hline Favorite team sport & $\mathrm{UEFA}^{\mathrm{d}}$ & Continuous \\
\hline Budget for women's football & UEFA $^{\mathrm{d}}$ & Continuous \\
\hline
\end{tabular}

aData came from the UEFA Women's Champions League Player List, provided by UEFA.

994 bData came from the official UEFA Women's Champions League website (http://www.uefa.com/womenschampionsleague/index.html).

995 cData came from the official FIFA website (http://www.fifa.com/fifa-world-ranking/ranking-table/women/index.html).

996 bata came from the Women's Football Across The National Associations yearly reports, provided by UEFA 
997 Table 2

998

999

1000

Descriptive Statistics for Coach-Level Variables

\begin{tabular}{|c|c|c|c|c|c|c|}
\hline Variables & $\begin{array}{l}\text { Code } \\
\text { or } \\
\text { Range }\end{array}$ & Median & $\begin{array}{l}\text { Mean } \\
\text { (SD) }\end{array}$ & $\begin{array}{l}\text { Valid } \\
\%(\mathrm{n})\end{array}$ & $\begin{array}{l}\text { Missing } \\
\%(\mathrm{n})\end{array}$ & $\begin{array}{c}\text { Included in } \\
\text { HLM } \\
\text { Model }\end{array}$ \\
\hline Age & $27-71$ & 43.00 & $\begin{array}{l}43.51 \\
(9.95)\end{array}$ & $\begin{array}{l}99.40 \\
(159)\end{array}$ & $.60(1)$ & Yes \\
\hline Gender & $0 / 1$ & & & $\begin{array}{l}100 \\
(160)\end{array}$ & $0(0)$ & Yes \\
\hline Male & 0 & & & $\begin{array}{l}85.60 \\
(137)\end{array}$ & - & \\
\hline Female & 1 & & & $\begin{array}{l}14.40 \\
(23)\end{array}$ & - & \\
\hline Nationality status & $0 / 1$ & & & $\begin{array}{l}100 \\
(160)\end{array}$ & $0(0)$ & Yes \\
\hline $\begin{array}{l}\text { Coaches team from outside native } \\
\text { country }\end{array}$ & 0 & & & $\begin{array}{l}8.10 \\
(13)\end{array}$ & - & \\
\hline Coaches team from native country & 1 & & & $\begin{array}{l}91.90 \\
(147)\end{array}$ & - & \\
\hline Former professional player & $0 / 1$ & & & $\begin{array}{l}68.10 \\
(109)\end{array}$ & $\begin{array}{c}31.90 \\
(51)\end{array}$ & No \\
\hline Did not play as a professional & 0 & & & $\begin{array}{l}54.10 \\
(59)\end{array}$ & - & \\
\hline Played as a professional & 1 & & & $\begin{array}{c}45.90 \\
(50)\end{array}$ & - & \\
\hline $\begin{array}{l}\text { Full national team playing } \\
\text { experience }\end{array}$ & $0 / 1$ & & & $\begin{array}{l}100 \\
(160)\end{array}$ & $0(0)$ & Yes \\
\hline Did not play on full national team & 0 & & & $\begin{array}{l}86.90 \\
(139)\end{array}$ & - & \\
\hline Played on full national team & 1 & & & $\begin{array}{l}13.10 \\
(21)\end{array}$ & - & \\
\hline International playing experience & $0 / 1$ & & & $\begin{array}{l}95.60 \\
(153)\end{array}$ & $4.40(7)$ & Yes \\
\hline Did not play internationally & 0 & & & $\begin{array}{l}88.90 \\
(136)\end{array}$ & - & \\
\hline $\begin{array}{l}\text { Played in World Cup, Olympics, or } \\
\text { Champions League }\end{array}$ & 1 & & & $\begin{array}{l}11.10 \\
(17)\end{array}$ & - & \\
\hline Position as a player & & & & $\begin{array}{l}45.00 \\
(72)\end{array}$ & $\begin{array}{c}55.00 \\
(88)\end{array}$ & No \\
\hline Goalkeeper & $0 / 1$ & & & $\begin{array}{c}13.90 \\
(10)\end{array}$ & - & \\
\hline Defender & 1 & & & $\begin{array}{c}13.90 \\
(10)\end{array}$ & - & \\
\hline Midfielder & 1 & & & $\begin{array}{c}43.10 \\
(31)\end{array}$ & - & \\
\hline Forward & 1 & & & $\begin{array}{c}29.10 \\
(21)\end{array}$ & - & \\
\hline
\end{tabular}


1005 Table \#2 - continued

1006

\begin{tabular}{|c|c|c|c|c|c|c|}
\hline Variables & $\begin{array}{l}\text { Code } \\
\text { or } \\
\text { Range }\end{array}$ & Median & $\begin{array}{l}\text { Mean } \\
\text { (SD) }\end{array}$ & $\begin{array}{l}\text { Valid } \\
\%(n)\end{array}$ & $\begin{array}{l}\text { Missing } \\
\%(\mathrm{n})\end{array}$ & $\begin{array}{l}\text { Included in } \\
\text { HLM } \\
\text { Model }\end{array}$ \\
\hline $\begin{array}{l}\text { Coaching experience of a national } \\
\text { team }\end{array}$ & $0 / 1$ & & & $\begin{array}{l}94.40 \\
(151)\end{array}$ & $5.60(9)$ & Yes \\
\hline $\begin{array}{l}\text { Did not coach a youth/full national } \\
\text { team }\end{array}$ & 0 & & & $\begin{array}{c}62.90 \\
(95)\end{array}$ & - & \\
\hline $\begin{array}{l}\text { Coached a youth/full national } \\
\text { team }\end{array}$ & 1 & & & $\begin{array}{c}37.10 \\
(56)\end{array}$ & - & \\
\hline $\begin{array}{l}\text { Years coaching experience in } \\
\text { Champions League }\end{array}$ & $0-4$ & 0.00 & $\begin{array}{c}0.81 \\
(1.00)\end{array}$ & $\begin{array}{l}100 \\
(160)\end{array}$ & $0(0)$ & Yes \\
\hline Time at current position & $0-24$ & 2.00 & $\begin{array}{c}3.36 \\
(4.51)\end{array}$ & $\begin{array}{l}98.80 \\
(158)\end{array}$ & $1.20(2)$ & Yes \\
\hline
\end{tabular}


1008 Table 3

1009

1010

Descriptive Statistics for Team-Level Variables

1011

\begin{tabular}{lcccccc}
\hline Variables & Range & Median & Mean (SD) & Valid \% (n) & $\begin{array}{c}\text { Missing } \\
\%(\mathrm{n})\end{array}$ & $\begin{array}{c}\text { Included } \\
\text { in HLM } \\
\text { Model }\end{array}$ \\
\hline $\begin{array}{l}\text { Number of times team has qualified for } \\
\text { Champions League }\end{array}$ & $0-6$ & 2.00 & $1.79(1.56)$ & $100(160)$ & $0(0)$ & Yes \\
$\begin{array}{l}\text { Number of times team has won } \\
\text { Champions League }\end{array}$ & $0-2$ & 0.00 & $0.11(.42)$ & $100(160)$ & $0(0)$ & Yes \\
$\begin{array}{l}\text { Number of international players } \\
\begin{array}{l}\text { Number of players with national team } \\
\text { experience }\end{array}\end{array}$ & $0-15$ & 4.00 & $4.40(3.43)$ & $99.40(159)$ & $.60(1)$ & Yes \\
\hline
\end{tabular}


1015 Table 4

1016

1017 Descriptive Statistics for Country-Level Variables

1018

\begin{tabular}{|c|c|c|c|c|c|c|}
\hline Variables & $\begin{array}{l}\text { Code or } \\
\text { Range }\end{array}$ & Median & Mean (SD) & Valid \% (n) & $\begin{array}{l}\text { Missing } \% \\
\text { (n) }\end{array}$ & $\begin{array}{c}\text { Included } \\
\text { in HLM } \\
\text { Model }\end{array}$ \\
\hline FIFA world ranking & $2-111$ & 17.50 & 22.72 & $98.80(158)$ & $1.20(2)$ & Yes \\
\hline Total number of divisions & $1-18$ & 4.00 & $4.21(2.06)$ & $93.10(149)$ & $6.90(11)$ & Yes \\
\hline Number of teams in top division & $5-20$ & 10.00 & $\begin{array}{l}10.55 \\
(2.60)\end{array}$ & $96.90(155)$ & $3.10(5)$ & Yes \\
\hline $\begin{array}{l}\text { Number of registered female } \\
\text { players* }\end{array}$ & $\begin{array}{c}100- \\
117,100\end{array}$ & 14,140 & $\begin{array}{c}21,287 \\
(24,216)\end{array}$ & $93.80(150)$ & $6.20(10)$ & Yes \\
\hline Favorite team sport & $0 / 1$ & - & - & $96.20(154)$ & $3.80(6)$ & Yes \\
\hline Any sport other than football & 0 & & & $40.30(62)$ & & \\
\hline Football & 1 & & & $59.70(92)$ & & \\
\hline Budget for women's football ${ }^{*}$ & $\begin{array}{c}51,600- \\
18,370,000\end{array}$ & $2,500,000$ & $\begin{array}{c}3,953,011 \\
(4,152,050)\end{array}$ & $95.60(153)$ & $4.40(7)$ & Yes \\
\hline
\end{tabular}


1021 Table 5

1022

1023 Multilevel Regression Estimates for the Null Unconditional Model

1024

\begin{tabular}{lcccc}
\hline Fixed Effect & Coefficient & SE & $t$-Ratio & $p$-value \\
\hline Intercept, $\gamma_{00}$ & 17.75 & 1.01 & 17.61 & $<.001$ \\
Random Effect & Variance & $d f$ & $x^{2}$ & $p$-value \\
Intercept, $u_{0}$ & 3.69 & 68 & 84.12 & .090 \\
Level-1 effect, $r_{i j}$ & 57.53 & & & \\
\hline
\end{tabular}

Reliability estimate for level-1= .19

Deviance 487.23; Number of estimated parameters $=2$

1025

1026 
1027 Table 6

1028

1029

Multilevel Regression Estimates for Two-Level Model A

1030

\begin{tabular}{lcccc}
\hline Fixed Effect & Coefficient & SE & $t$-Ratio & $p$-value \\
\hline Intercept, $\gamma_{00}$ & 14.25 & 6.63 & 2.15 & .04 \\
Age, $\gamma_{10}$ & -0.01 & 0.10 & -0.14 & .90 \\
Gender, $\gamma_{20}$ & 0.95 & 4.85 & 0.20 & .85 \\
Nationality status, $\gamma_{30}$ & 6.10 & 5.33 & 1.15 & .26 \\
Full national team playing experience, $\gamma_{40}$ & 1.50 & 5.11 & 0.29 & .77 \\
Coaching experience of a national & 4.38 & 2.48 & 1.77 & .08 \\
team, $\gamma_{50}$ & -4.30 & 3.91 & -1.10 & .28 \\
International playing experience, $\gamma_{60}$ & -4.29 & 1.58 & -2.71 & .01 \\
Years coaching experience in Champions & -0.04 & .37 & -0.11 & .91 \\
League, $\gamma_{70}$ & Variance & $d f$ & $x^{2}$ & $p$-value \\
Time at current position, $\gamma_{80}$ & 3.43 & 68 & 72.35 & .34 \\
Random Effect & 57.35 & & & \\
Intercept, $u_{0}$ & & & & \\
Level-1 effect, $r_{i j}$ & & &
\end{tabular}

Reliability estimate for level- $1=.17$

Deviance $=453.24$; Number of estimated parameters $=2$

1031

1032 
1033 Table 7

1034

1035

Multilevel Regression Estimates for Two-Level Model B

\begin{tabular}{lcccc}
\hline Fixed Effect & Coefficient & SE & $t$-Ratio & $p$-value \\
\hline Intercept, $\gamma_{00}$ & 20.02 & 1.32 & 15.16 & $<.001$ \\
Years coaching experience in Champions & -3.63 & 1.46 & -2.49 & .015 \\
League, $\gamma_{10}$ & Variance & $d f$ & $x^{2}$ & $p$-value \\
Random Effect & 3.53 & 68 & 82.62 & .109 \\
Intercept, $u_{0}$ & 53.59 & & & \\
Level-1 effect, $r_{i j}$ & & & & \\
\hline
\end{tabular}

Reliability estimate for level-1 $=.19$

Deviance $=476.77$; Number of estimated parameters $=2$

1036

1037 
1038 Table 8

1039

1040 Multilevel Regression Estimates for Two-Level Model C

\begin{tabular}{lcccc}
\hline Fixed Effect & Coefficient & SE & $t$-Ratio & $p$-value \\
\hline Intercept, $\gamma_{00}$ & 24.56 & 1.43 & 17.23 & $<.001$ \\
$\begin{array}{l}\text { Number of times team has won Champions } \\
\text { League, } \gamma_{01}\end{array}$ & -7.13 & 1.83 & -3.89 & $<.001$ \\
Number of international players, $\gamma_{02}$ & -1.08 & 0.25 & -4.26 & $<.001$ \\
Years coaching experience in Champions & -2.90 & 1.37 & -2.12 & .038 \\
League, $\gamma_{10}$ & Variance & $d f$ & $x^{2}$ & $p$-value \\
Random Effect & 9.24 & 66 & 80.15 & .113 \\
Intercept, $r_{0}$ & 39.64 & & & \\
Level-1 effect $r_{i j}$ & & & & \\
\hline
\end{tabular}

Reliability estimate for level-1 $=.19$

Deviance $=451.28$; Number of estimated parameters $=2$

1041

1042

1043

1044 
1045 Table 9

1046

1047

1048

Multilevel Regression Estimates for Three-Level Model D

\begin{tabular}{lcccc}
\hline Fixed Effect & Coefficient & SE & $t$-Ratio & $p$-value \\
\hline Intercept, $\gamma_{000}$ & 21.85 & 1.53 & 14.25 & $<.001$ \\
FIFA world ranking, $\gamma_{001}$ & 0.09 & 0.03 & 3.03 & .005 \\
Number of times team has won Champions & -5.79 & 1.87 & -3.10 & .004 \\
League, $\gamma_{010}$ & -1.25 & 0.25 & -4.99 & $<.001$ \\
Number of international players, $\gamma_{020}$ & -0.81 & 1.49 & -0.54 & $p>.05$ \\
Years coaching experience in Champions & Variance & $d f$ & $x^{2}$ & $p$-value \\
League, $\gamma_{100}$ & 1.80 & 32 & 37.52 & .23 \\
Random Effect Level-3 & & & & \\
Intercept 1/Intercept $2, u_{00}$ & & & & \\
Reliability estimate for level-1 $=.99$ & & & \\
Reliability estimate for level-2 $=.12$ & & & & \\
Deviance $=215.20 ;$ Number of estimated parameters $=7$ & & & \\
\hline
\end{tabular}

1049

1050

1051 


\section{Dependent Variable Final Rank}

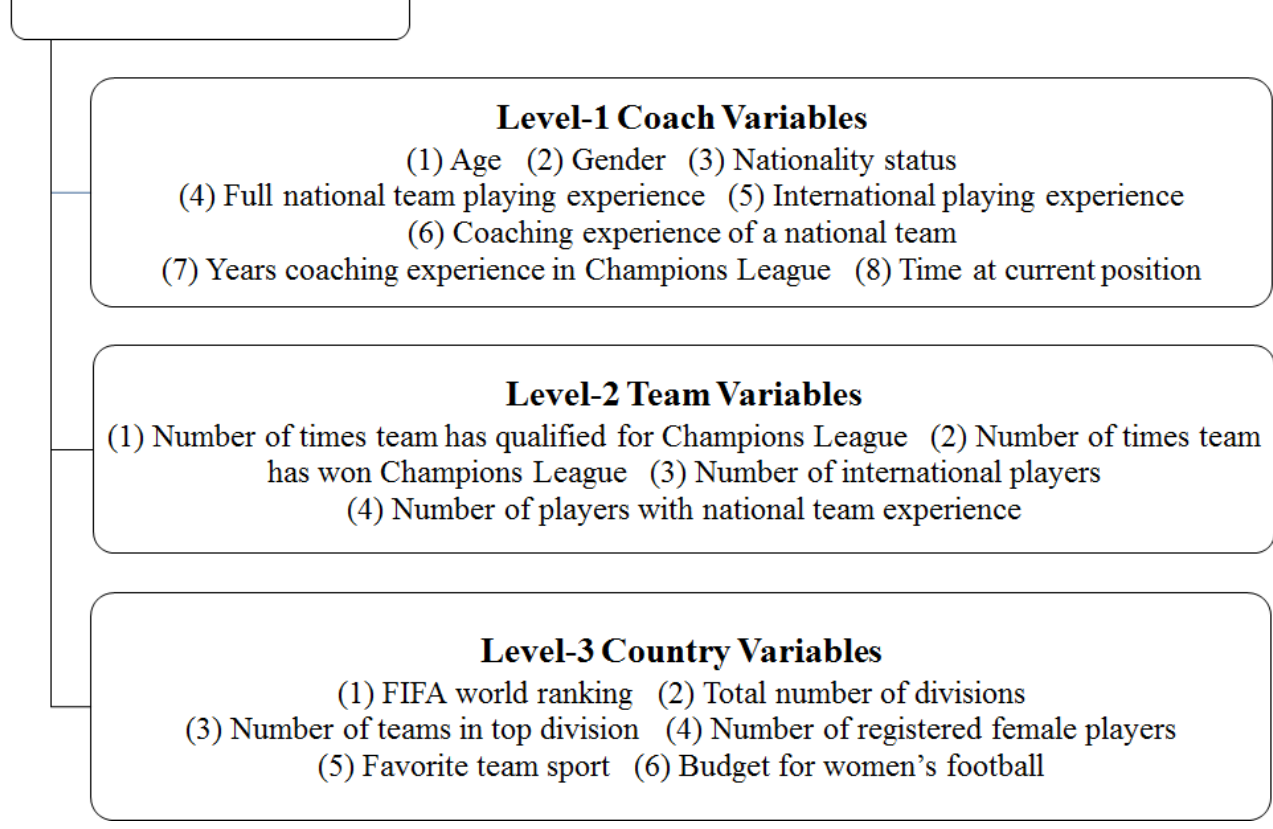




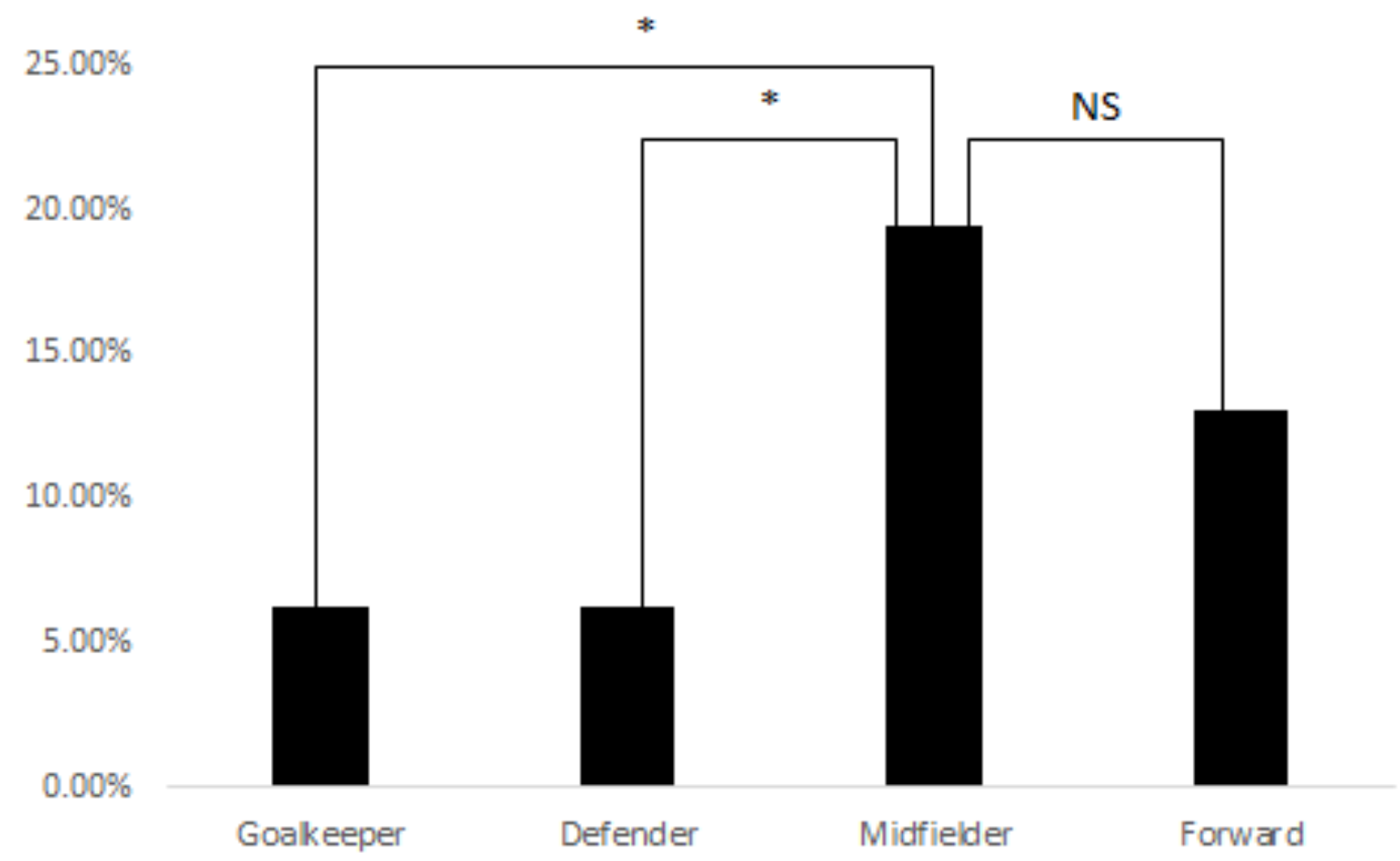

1065

1066

1067

1068

Note. ${ }^{*} p<.01$

1069

Figure 2. Playing position of coaches.

1070

1071 
Panel A

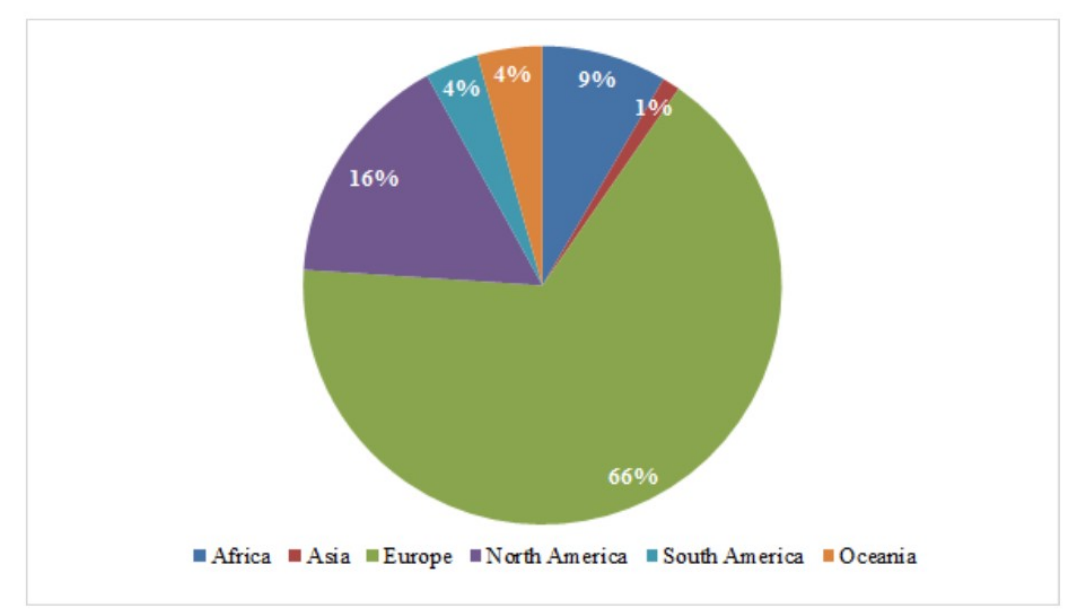

Panel B

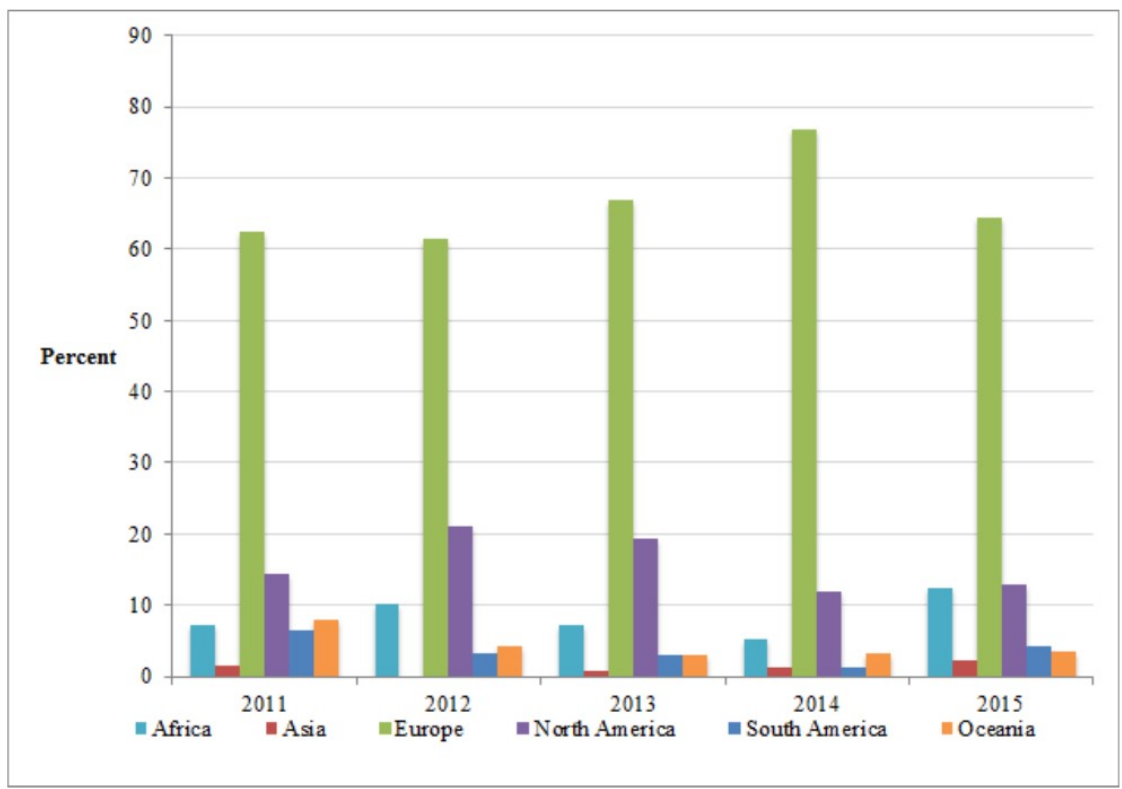

1073 Figure 3. Overall proportion of international players per continent competing in the UEFA 1074 Women's Champions League from 2011-12 to 2015-16 (Panel A). Proportion of international 1075 players per continent by year (Panel B). 
1082

\section{Panel A}

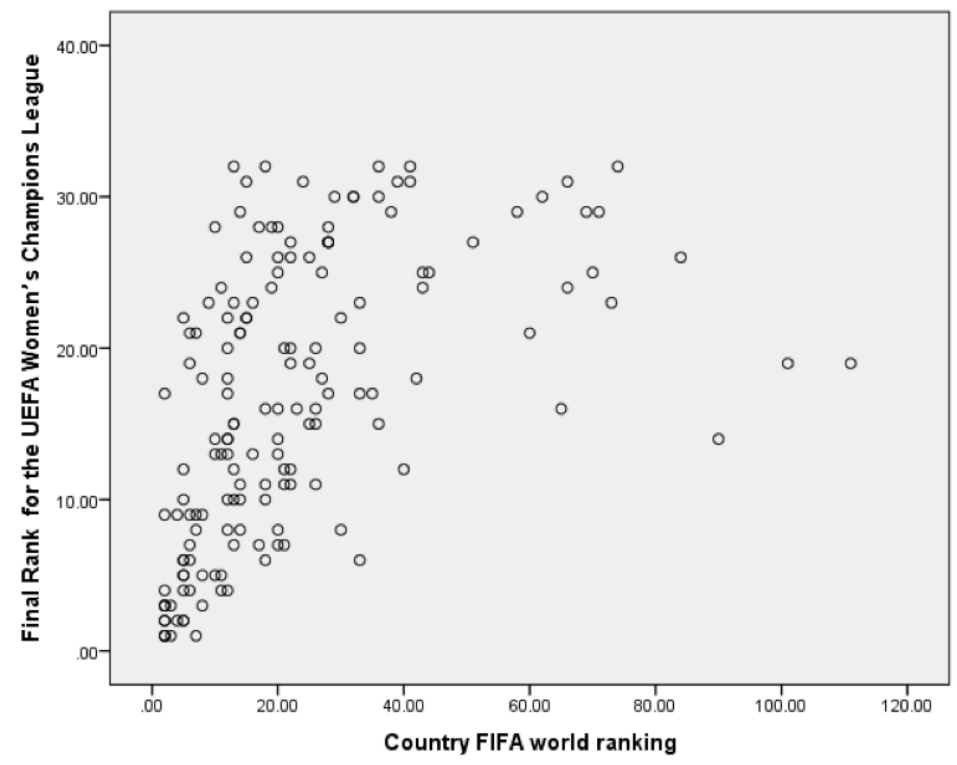

\section{Panel B}

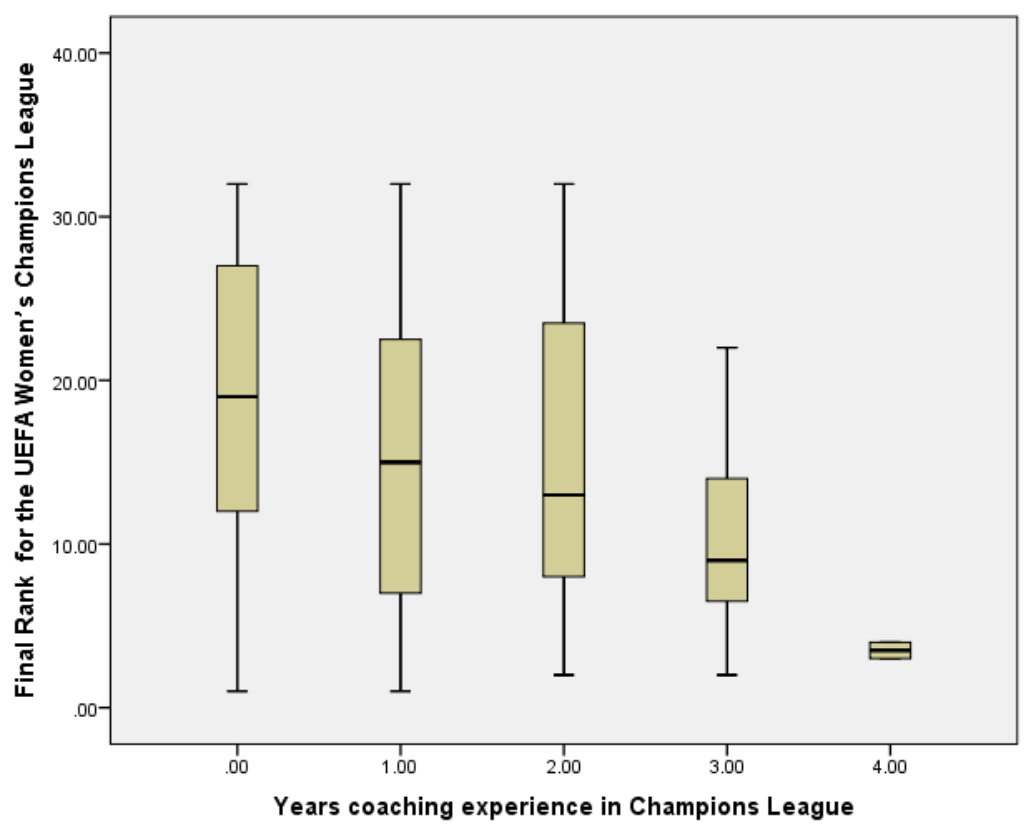

Figure 4. Relationship between country FIFA world ranking and final rank for the UEFA Women's Champions League (Panel A). Relationship between years coaching experience in Champions League and final rank for the UEFA Women's Champions League (Panel B). 
Coaches' Characteristics

(Level-1 Data)

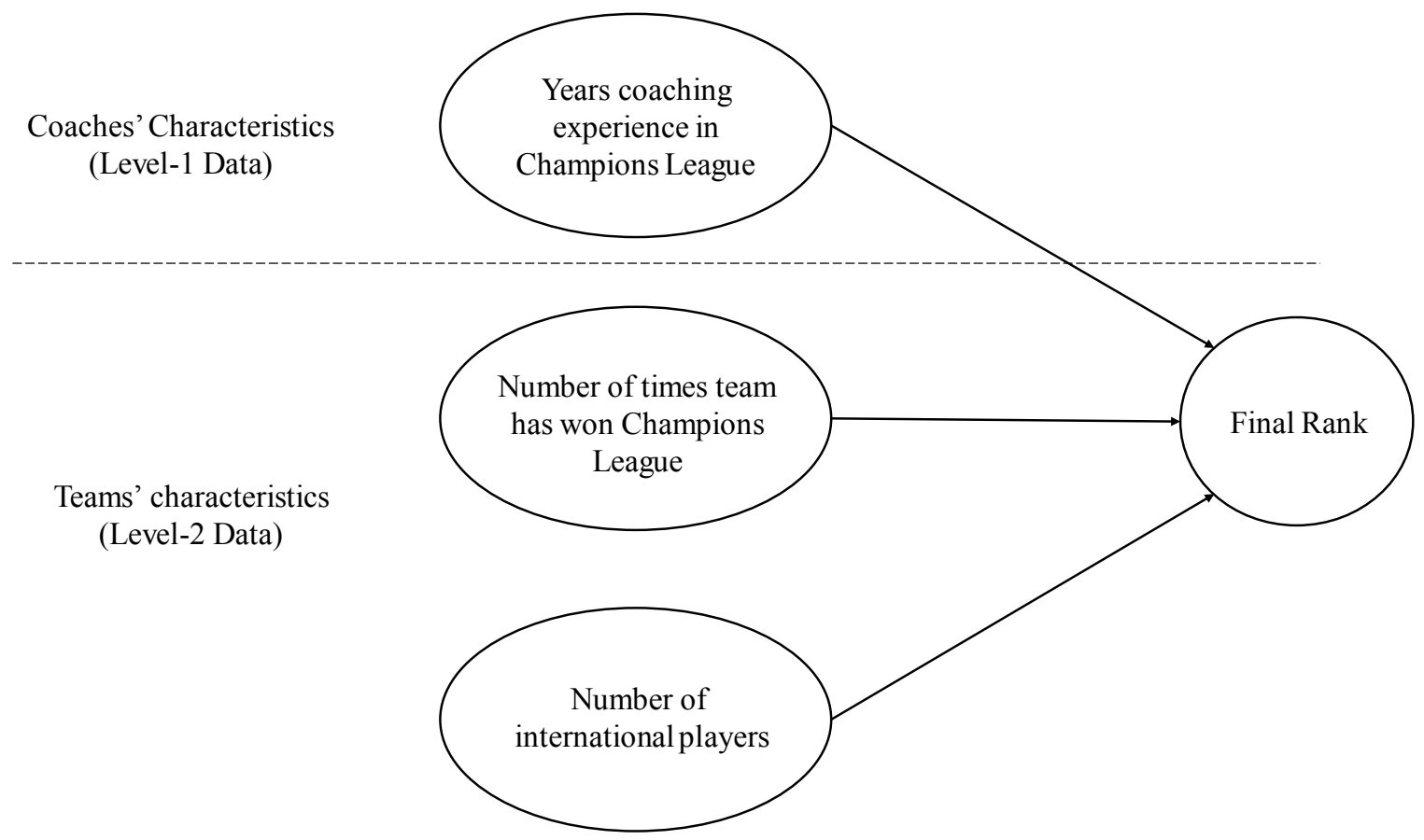

